\title{
A Universal Power Flow Model for Dual Active Bridge Based Converters with Phase Shift Modulation
}

Xiao, Yudi; Zhang, Zhe; Manez, Kevin Tomas; Andersen, Michael A. E.

Published in:

IEEE Transactions on Power Electronics

Link to article, DOI:

10.1109/TPEL.2020.3039195

Publication date:

2021

Document Version

Peer reviewed version

Link back to DTU Orbit

Citation (APA):

Xiao, Y., Zhang, Z., Manez, K. T., \& Andersen, M. A. E. (2021). A Universal Power Flow Model for Dual Active Bridge Based Converters with Phase Shift Modulation. IEEE Transactions on Power Electronics, 36(6), 6480 6500. https://doi.org/10.1109/TPEL.2020.3039195

\section{General rights}

Copyright and moral rights for the publications made accessible in the public portal are retained by the authors and/or other copyright owners and it is a condition of accessing publications that users recognise and abide by the legal requirements associated with these rights.

- Users may download and print one copy of any publication from the public portal for the purpose of private study or research.

- You may not further distribute the material or use it for any profit-making activity or commercial gain

- You may freely distribute the URL identifying the publication in the public portal 


\title{
A Universal Power Flow Model for Dual Active Bridge Based Converters with Phase Shift Modulation
}

\author{
Yudi Xiao, Student Member, IEEE, Zhe Zhang, Senior Member, IEEE, \\ Kevin Tomas Manez, and Michael A.E. Andersen, Member, IEEE
}

\begin{abstract}
In this paper, a universal power flow model for the Dual Active Bridge (DAB) based dc-dc converters with phase-shift modulation is derived. The model considers the lossy components, the dead time, and the resonant commutations of the converters. A power flow model for the Partial Parallel Dual Active Bridge $\left(P^{2} D A B\right)$ converter is generated from the universal power flow model. Based on the calculations, the power plateau phenomenon and the anti-power phenomenon, as well as their causes and influences are discussed. Because of the zero-reactivepower-loss in the lagging full-bridge, the zero-voltage-turn-on of all of the switches, and the zero-current-commutation of the switches in the lagging full-bridge during the power plateau, a hypothesis, which claims that the converter is more efficient in the power plateau operation than in other operation modes, is made. A laboratory prototype of the $P^{2} D A B$ converter is constructed. The analysis about the power plateau and the antipower phenomenon is verified, as well as the proposed hypothesis is proved. Compared against the measured power, the model for the $\left(P^{2} D A B\right)$ converter has the maximum error less than $10 \%$. Therefore, the validity of the universal power flow model is verified.
\end{abstract}

Index Terms-Bidirectional dc-dc converter, dual active bridge, phase-shift modulation, power flow model

\section{INTRODUCTION}

$\mathbf{O}$ VER the past few years renewable energy resources (RES), such as solar power and wind power, have experienced strong developments to become alternatives for conventional energy resources due to global awareness on the limited fossil fuel resources and their environmental impacts. However, the large-scale integration of RES into the grid will degrade the grid reliability because of the highly irregular and mostly unpredictable generation of RES. Therefore, solutions such as energy storage system (ESS) are required to improve the grid stability and reliability [1]. Bidirectional converters, which can interface ESS to power conversion systems, have gained increasing attention [2]- [4]. The basic requirements of the converter used for interfacing ESS to power conversion system mainly include galvanic isolation and bidirectional power flow capability.

Manuscript received on 15-Apr-2020, revised on 05-Aug-2020 and 01-Oct2020 and accepted on 11-Nov-2020. (Corresponding author: Zhe Zhang.)

Yudi Xiao, Zhe Zhang and Michael A.E. Andersen are with the Department of Electrical Engineering, Technical University of Denmark, 2800, Kongens Lyngby, Denmark (e-mail: yudxiao@elektro.dtu.dk; zz@elektro.dtu.dk; ma@elektro.dtu.dk)

Kevin Tomas Manez is with IDNEO Technologies, Mollet del Valles, Spain. (e-mail: ktomasmanez@gmail.com)

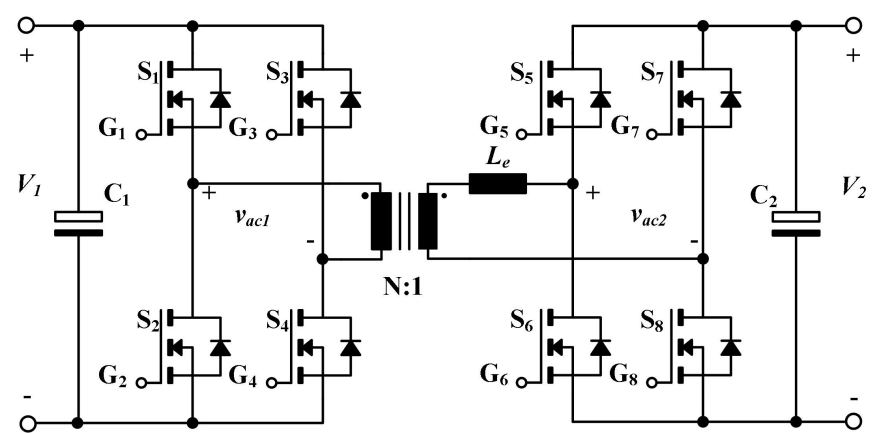

Fig. 1: Topology of the DAB converter

Among all of the topologies, the Dual Active Bridge (DAB) converters and the resonant converters are the most common ones due to their advantages in soft switching and simple topologies, etc [5]- [13]. Compared to the resonant converters, the DAB converters has simpler structures, easier control methods and symmetrical configurations. The topology of the single-phase DAB converter is shown in Fig. 1. The two active full-bridges are modulated to apply ac voltages across the inductor to control the inductor current, which together with the two ac voltages determine the power flow of the converter. The basic modulation strategy is the phase-shift modulation (PSM), where both full-bridges are modulated to generate square waves, while the power flow is controlled by adjusting the phase shift between these two square waves [14] [15]. A few researches have been done to explore the power flow characteristics of the DAB converter with PSM [16]- [20]. In [16], the short-time-scale transient processes in DAB converters with SPSM were discussed. However, no improvements in the power flow equation were made. In [17], an improved power flow equation was derived considering the dead-time effect and voltage drops of power switches, but the equation is not suitable for the DAB converters using power MOSFETs; moreover the analyzed cases are limited. In [18], the power flow equation was derived considering MOSFET's ON resistance, and parasitic resistances of the inductor, transformer and PCB traces; however, the dead time effect was somehow neglected. In [19], a lossless power flow model was derived considering dead times. With the model, some power flow characteristics were given, including the power plateau phenomenon which are further investigated in [20]. In [20], a power flow model considering the dead 


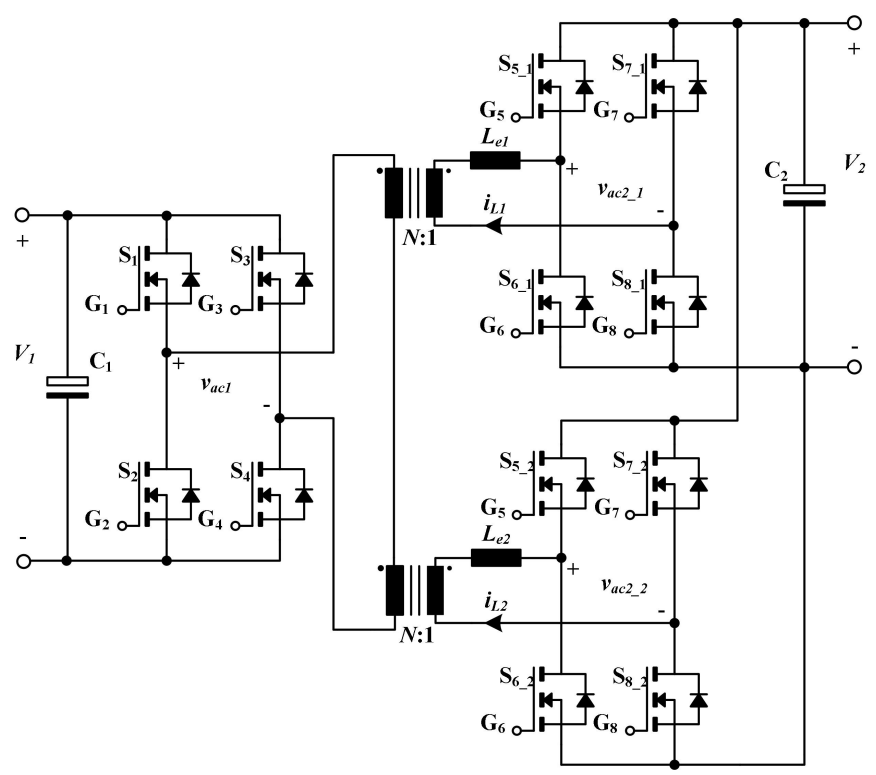

Fig. 2: Topology of the $\mathrm{P}^{2} \mathrm{DAB}$ converter

time and the lossy elements, i.e. switches' on-state resistance, voltage drop in reverse conduction, winding resistances of magnetic components, is derived for the $\mathrm{DAB}$ converter with PSM. This model will be referred as DAB-model-1 in the rest of this paper. The power plateau phenomenon is discussed and the anti-power phenomenon is discovered. The derivation of the model is based on a equivalent circuit. Therefore, the model potentially could be used to calculate the power flow of DAB based converters having the same equivalent circuit. In [21], a so-called Partial Parallel Dual Active Bridge $\left(\mathrm{P}^{2} \mathrm{DAB}\right)$ converter, whose topology is shown in Fig. 2, is proposed. As shown, in the $\mathrm{P}^{2} \mathrm{DAB}$ converter, the circuit parts, which need to carry high current, are connected in parallel. The circuit parts, which need to block high voltage, are connected in series. Benefits of using the $\mathrm{P}^{2} \mathrm{DAB}$ converter includes:(1) the ac current balancing between the paralleled bridges on the low-voltage (LV) side are inherently ensured by the serially connected windings on the high-voltage (HV) side. (2) additional phase shift can be applied between the paralleled bridges on the LV side to extend the zero-voltageswitching (ZVS) range. (3) one or more paralleled bridges on the LV side can be modulated in self-circulating mode to change the voltage gain of the $\mathrm{P}^{2} \mathrm{DAB}$ converter [22]. In [23], the power flow models of the $\mathrm{P}^{2} \mathrm{DAB}$ converter with PSM is derived. This model will be referred as $\mathrm{P}^{2} \mathrm{DAB}$-model-1 in the rest of this paper. Since the $\mathrm{P}^{2} \mathrm{DAB}$ converter with PSM shares the same equivalent circuit as the DAB converter with PSM, $\mathrm{P}^{2} \mathrm{DAB}$-model-1 is simply a extension of DAB-model1. DAB-model-1 and $\mathrm{P}^{2} \mathrm{DAB}$-model-1 are able to predict the power plateau phenomenon and the anti-power phenomenon. However, there is still errors between the calculated power and the measured power. In [23], the maximum error in predicting output power is $23 \%$.

This paper is an extension of [20] and [23]. After this introduction, in Section II, DAB-model-1 is modified to be a universal power flow model for DAB-based converters wih

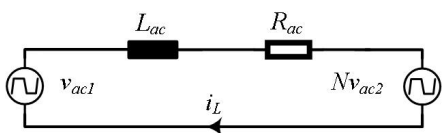

Fig. 3: Equivalent circuit for the DAB converter with PSM

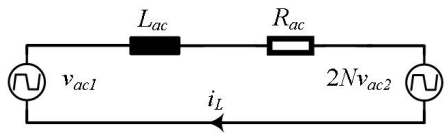

Fig. 4: Equivalent circuit for the $\mathrm{P}^{2} \mathrm{DAB}$ converter with PSM

PSM. The cause of the error in DAB-model- 1 and $\mathrm{P}^{2} \mathrm{DAB}-$ model-1 is determined to be the resonant commutation of switches. The resonant commutation is thereby considered in an improved universal power flow model. In Section III, the improved universal power flow model is applied to the $\mathrm{P}^{2} \mathrm{DAB}$ converter to generate $\mathrm{P}^{2} \mathrm{DAB}$-model-2. The power flow characteristics of the $\mathrm{P}^{2} \mathrm{DAB}$ converter is analyzed based on $\mathrm{P}^{2} \mathrm{DAB}-$ model-2. The power plateau phenomenon and the anti-power phenomenon of the $\mathrm{P}^{2} \mathrm{DAB}$ converter is discussed in detail. Another power flow phenomenon, namely the efficient power plateau, is discovered and discussed for the first time. In Section IV, the power plateau phenomenon and the anti-power phenomenon is verified on a $\mathrm{P}^{2} \mathrm{DAB}$ prototype. Compared to $\mathrm{P}^{2} \mathrm{DAB}$-model-1, the length and location of the power plateau predicted by $\mathrm{P}^{2} \mathrm{DAB}-$ model-2 is closer to the measurements. The efficient power plateau is verified on the $\mathrm{P}^{2} \mathrm{DAB}$ prototype. The error of $\mathrm{P}^{2} \mathrm{DAB}$-model-2 is less than $10 \%$, compared to $23 \%$ of $\mathrm{P}^{2} \mathrm{DAB}$-model-1. Conclusions are made in Section V.

\section{Power Flow Models for DAB-BASEd CONVERTERS WITH PSM}

\section{A. DAB-model-1 and P2DAB-model-1}

DAB-model-1 is derived in [20], where the DAB converter is simplified as the equivalent circuit shown in Fig. 3. $v_{a c 1}$ and $v_{a c 2}$ are the switching node voltage of the bridges connected to $V_{1}$ and $V_{2}$, respectively. $L_{a c}$ and $R_{a c}$ are expressed as:

$$
\begin{gathered}
L_{a c}=L_{t r p}+N^{2} L_{t r s}+L_{e} \\
R_{a c}=R_{t r p}+N^{2} R_{t r s}+R_{e}
\end{gathered}
$$

where $L_{e}$ and $R_{e}$ represent the inductance and winding resistance of the external inductor; $L_{t r p}, R_{t r p}$ and $L_{t r s}, R_{t r s}$ represent the leakage inductance and the winding resistance of the transformer, on primary side and secondary side, respectively. Depending on the modulation of the two bridges, $v_{a c 1}, v_{a c 2}$ and $i_{L}$ are modeled, and so as the power flow. A detailed derivation will be presented in the derivation of the universal

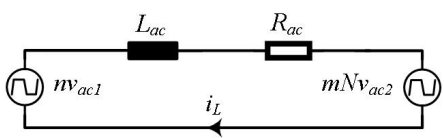

Fig. 5: Equivalent circuit for the DAB-based converters with PSM 


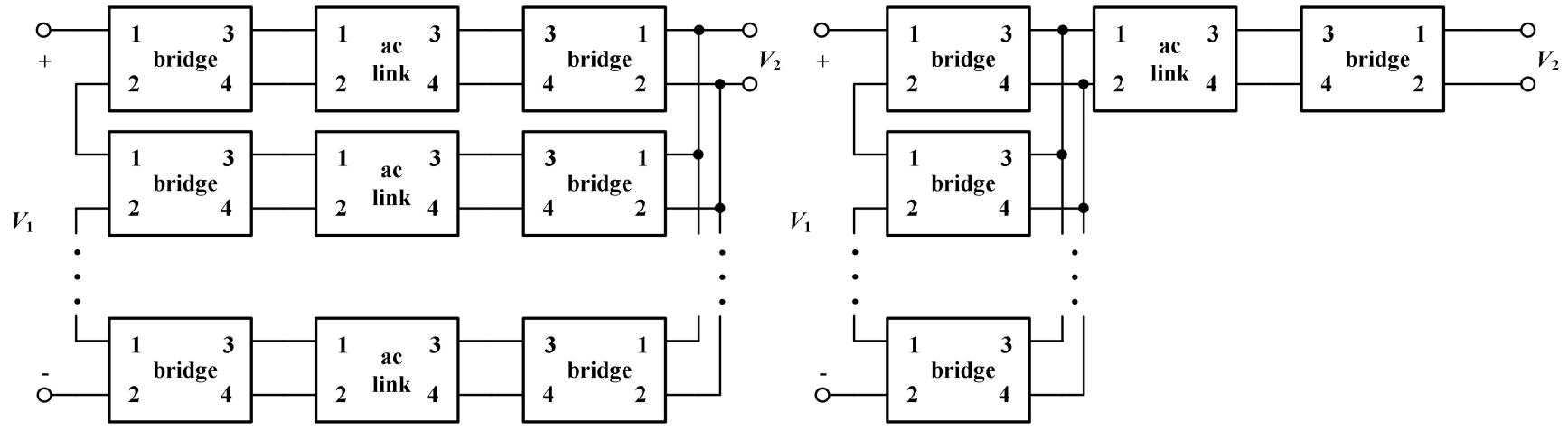

(a) Mod 1

(d) Mod 4

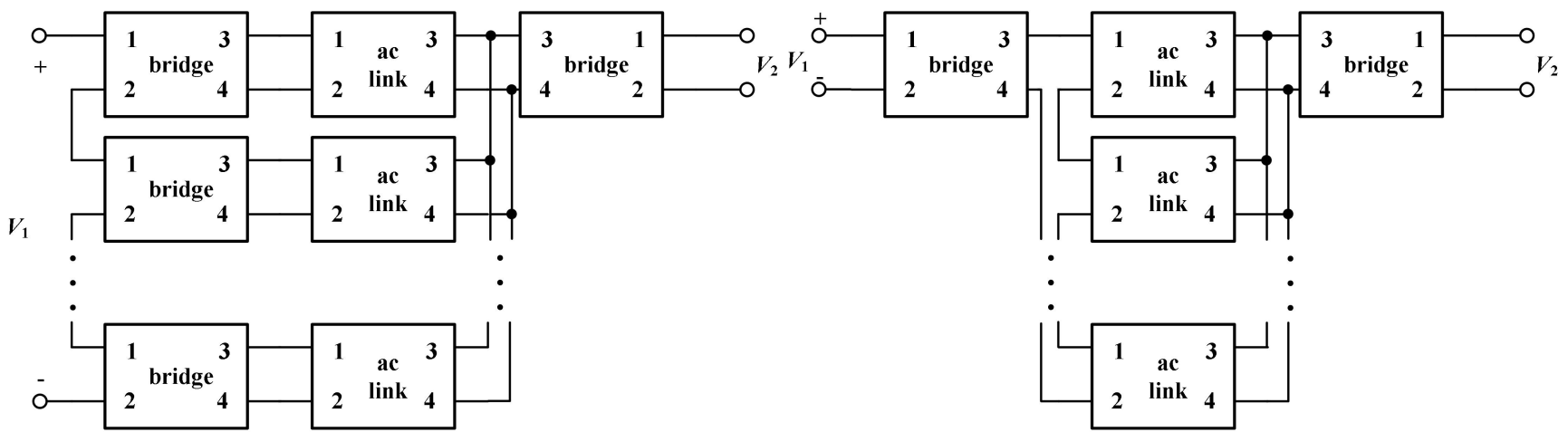

(b) Mod 2

(e) Mod 5

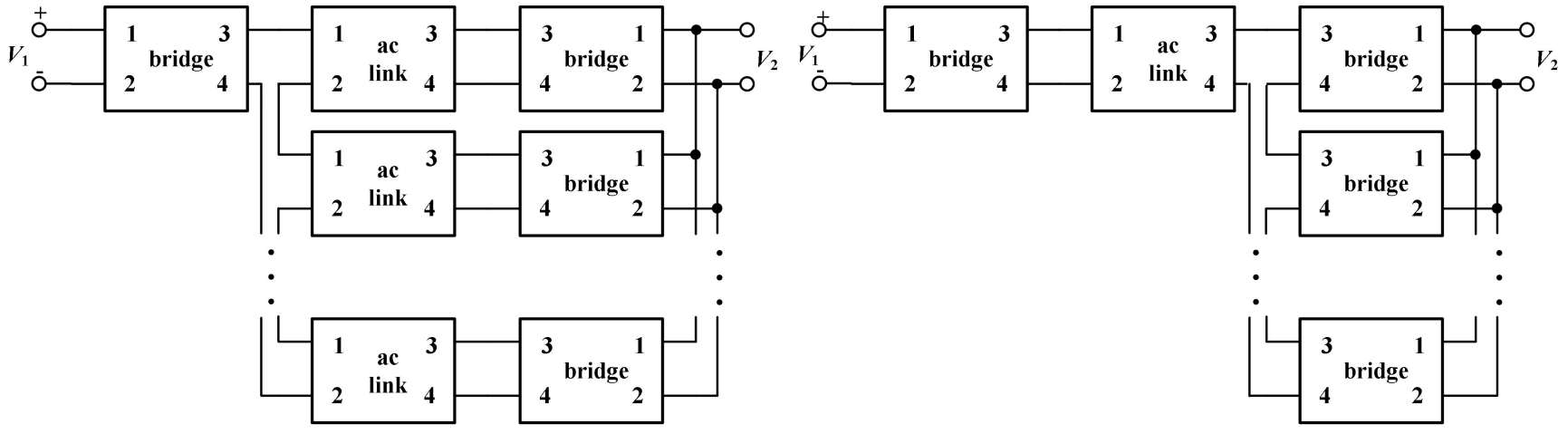

(c) Mod 3

(f) Mod 6

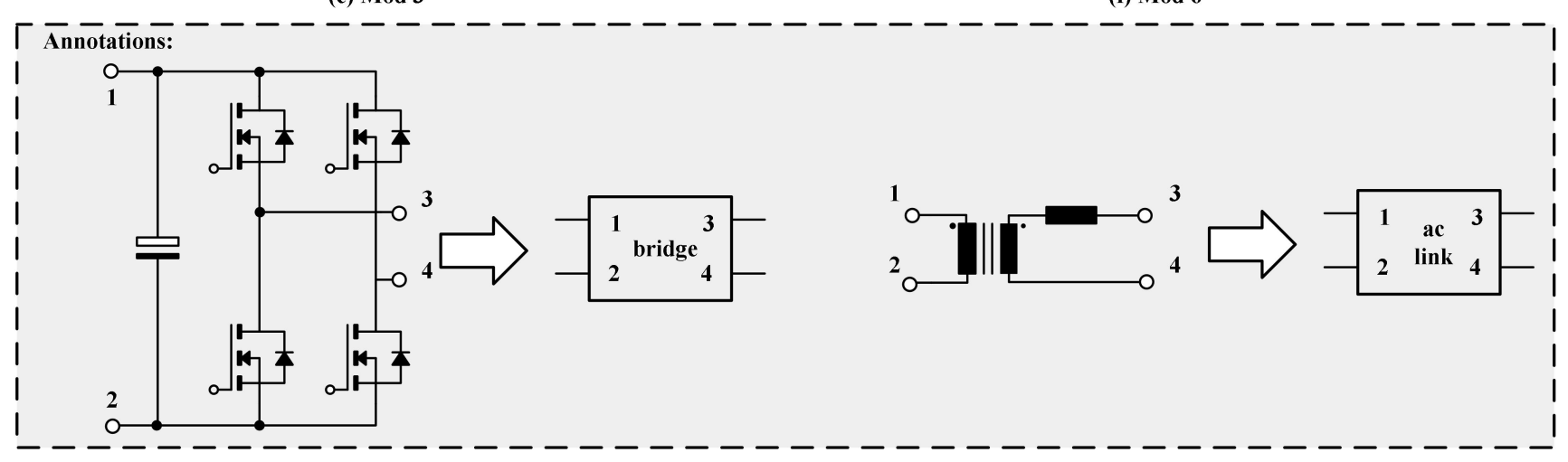

Fig. 6: ISOP modular structures based on the DAB converter 
power flow model in the next subsection. As shown in Fig. 3 , the modeling of the power flow is actually modeling of the ac link. The active circuit parts, i.e. the two bridges, are represented by their switching node voltages, respectively. The circuit elements in the ac link are referred to one side of the transformer. In this case, it is the left side in Fig. 3.

$\mathrm{P}^{2}$ DAB-model-1 is derived in [23]. The circuit elements considered in $\mathrm{P}^{2} \mathrm{DAB}-$ model-1 are the same to those considered in DAB-model-1. In order to derive the power flow model of the converter, the $\mathrm{P}^{2} \mathrm{DAB}$ converter is simplified as the equivalent circuit shown in Fig. 4. The power flow is then modeled by modeling the ac link. Since there are two transformers and two inductors in the $\mathrm{P}^{2} \mathrm{DAB}$ converter, $L_{a c 2}$ and $R_{a c 2}$ can be expressed as:

$$
\begin{gathered}
L_{a c 2}=2\left(L_{t r p}+N^{2} L_{t r s}+L_{e}\right) \\
R_{a c 2}=2\left(R_{t r p}+N^{2} R_{t r s}+R_{e}\right)
\end{gathered}
$$

Due to the series connection of the primary side of the transformer and the parallel connection of the DC rails of two bridges on the right, the ac voltage source on the right in Fig. 4 is two times of $N v_{a c 2}$. Note that the two bridges on the right in Fig. 2 are identically modulated. Their switching node voltages are thereby identical to each other and are referred as $v_{a c 2}$ here.

\section{B. Universal Power Flow Models for DAB-based converters with PSM}

The DAB converter has been intensively used in modular or multicell structures, as an alternative to increase the voltage and current levels handled by the power converters [24]. Given that the DAB converter is composed by three circuit parts, i.e. as shown in Fig. 1, the bridge on the left, the ac link in the middle, and the bridge on the right. Therefore, there are 6 ways to compose the module. Consider that the modules can be connected in 4 ways, i.e. input-series-output-parallel (ISOP), input-parallel-output-series (IPOS), both-series (SS), and bothparallel (PP), there are at least 24 modular structures based on the DAB converter. Fig. 6 shows the 6 ISOP modular structures based on the DAB converter. The topology of the remaining 18 are not given. However, the coefficients associated with each of the 24 structures in the universal power flow model are given in Table. I. With the coefficients in Table. I and the universal power flow models that will be derived later, the power flow of all of the 24 modular structures can be calculated.

The least complicated modulation of the modular converters based on the DAB converter would be PSM. In a modular structure, PSM would mean applying a phase shift between the bridges isolated by the ac link, while identically modulating the bridges that are commonly grounded. In the rest of this paper, the modular converters based on the DAB converter with PSM will be referred as DAB-based converters with PSM.

1) Overview of Derivation: The derivation that will be presented in this subsection is complicated. Providing an overview of the derivation is thereby necessary. Fig. 7 gives the flowchart of the derivation. As shown, the model considers the variation of module structure, dead time, on-resistance and reverse voltage drop of switches and the parasitic elements of

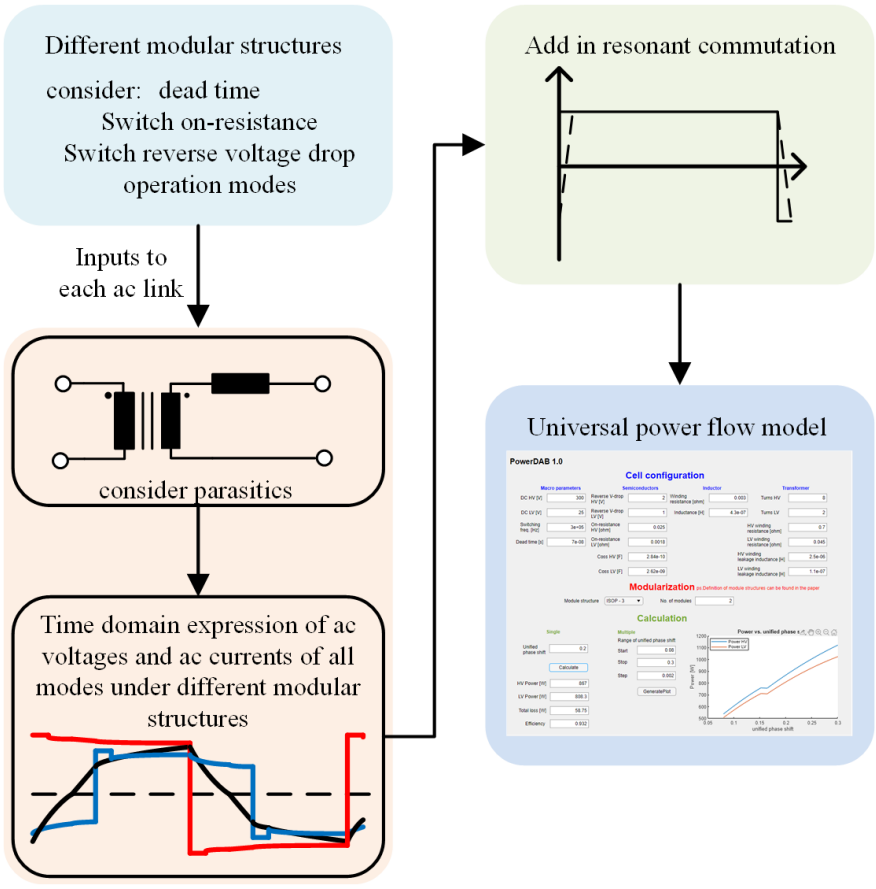

Fig. 7: Flowchart of deriving the universal power flow models

the magnetic components. The time domain expressions of the ac voltages and ac currents are derived. With the expression of ac currents, the input and output current can be calculated, and hence the input and output power can be calculated. Resonant commutation is then added into the model to improve the accuracy.

2) Basic Universal Power Flow Model: As shown in Fig. 3 and Fig. 4, the equivalent circuits for modeling power flow of the DAB converter with PSM and the $\mathrm{P}^{2} \mathrm{DAB}$ converter with PSM have the same topology, i.e. a topology with two ac voltage sources connected by an inductive element and a resistive element in series. The universal equivalent circuit for DAB-based converters with PSM is given in Fig. 5. As shown, it has the same topology as well. $n, \operatorname{Mag}\left(v_{a c 1}\right)$ (magnitude of $v_{a c 1}$ ), $m$, and $\operatorname{Mag}\left(v_{a c 2}\right)$ (magnitude of $v_{a c 2}$ ) for a list of DABbased converters with PSM are given in Table. I, where $N_{m}$ is the number of modules. Also given in Table. I are $k_{i n}, k_{o}, k_{\text {rin }}$, and $k_{r o}$, which will be used later in this subsection.

Given the universal equivalent circuit, in order to calculate the power flowing through the ac link, the waveforms of $v_{a c 1}$ and $v_{a c 2}$ need to be specified. $v_{a c 1}$ and $v_{a c 2}$ are no longer square waves as in ideal cases [14]. $L_{a c}$ and $R_{a c}$ will introduce decaying feature into $v_{a c 1}, v_{a c 2}$ and $v_{a c 1}$ and $i_{L}$. The voltage drop during reverse conduction of the switches will introduce discontinuity into $v_{a c 1}$ and $v_{a c 2}$. Especially with the use of GaN devices, whose voltage drop during reverse conduction is much larger than Silicon devices. The waveforms of $v_{a c 1}$, $v_{a c 2}$ and $v_{a c 1}$ and $i_{L}$ for $V_{1} \rightarrow V_{2}$ are given in Fig. 8. $V_{1} \rightarrow V_{2}$ denotes the operation where power flows from $V_{1}$ to $V_{2}$, and $V_{2} \rightarrow V_{1}$ vice versa. The operation conditions for Mode $a-$ Mode $i$ in Fig. 8 are summarized in Table. II. The waveforms for $V_{2} \rightarrow V_{1}$ are of the same pattern, therefore are not given in 
TABLE I: $n, \operatorname{Mag}\left(v_{a c 1}\right), m, \operatorname{Mag}\left(v_{a c 2}\right), k_{i n}, k_{o}, k_{r i n}$, and $k_{r o}$ for different DAB-based converters with PSM

\begin{tabular}{l|l|l|l|l|l|l|l|l} 
module & $\boldsymbol{n}$ & $\begin{array}{l}\text { Mag } \\
\left(v_{a c 1}\right)\end{array}$ & $\boldsymbol{m}$ & $\begin{array}{l}\text { Mag } \\
\left(v_{a c 2}\right)\end{array}$ & $k_{\text {in }}$ & $k_{o}$ & $k_{\text {rin }}$ & $k_{\text {ro }}$ \\
\hline ISOP-1 & 1 & $V_{1} / N_{m}$ & 1 & $V_{2}$ & 1 & $N_{m}$ & 1 & 1 \\
ISOP-2 & 1 & $V_{1} / N_{m}$ & 1 & $V_{2}$ & 1 & $N_{m}$ & 1 & $N_{m}$ \\
ISOP-3 & $1 / N_{m}$ & $V_{1}$ & 1 & $V_{2}$ & 1 & $N_{m}$ & 1 & 1 \\
ISOP-4 & 1 & $V_{1} / N_{m}$ & 1 & $V_{2}$ & $1 / N_{m}$ & 1 & $1 / N_{m}$ & 1 \\
ISOP-5 & $1 / N_{m}$ & $V_{1}$ & 1 & $V_{2}$ & 1 & $N_{m}$ & 1 & $N_{m}$ \\
ISOP-6 & 1 & $V_{1}$ & $N_{m}$ & $V_{2}$ & 1 & $N_{m}$ & 1 & 1 \\
\hline IPOS-1 & 1 & $V_{1}$ & 1 & $V_{2} / N_{m}$ & $N_{m}$ & 1 & 1 & 1 \\
IPOS-2 & 1 & $V_{1}$ & $1 / N_{m}$ & $V_{2}$ & $N_{m}$ & 1 & 1 & 1 \\
IPOS-3 & 1 & $V_{1}$ & 1 & $V_{2} / N_{m}$ & $N_{m}$ & 1 & $N_{m}$ & 1 \\
IPOS-4 & $N_{m}$ & $V_{1}$ & 1 & $V_{2}$ & $N_{m}$ & 1 & 1 & 1 \\
IPOS-5 & 1 & $V_{1}$ & $1 / N_{m}$ & $V_{2}$ & $N_{m}$ & 1 & $N_{m}$ & 1 \\
IPOS-6 & 1 & $V_{1}$ & 1 & $V_{2} / N_{m}$ & 1 & $1 / N_{m}$ & 1 & $1 / N_{m}$ \\
\hline SS-1 & 1 & $V_{1} / N_{m}$ & 1 & $V_{2} / N_{m}$ & 1 & 1 & 1 & 1 \\
SS-2 & 1 & $V_{1} / N_{m}$ & $1 / N_{m}$ & $V_{2}$ & 1 & 1 & 1 & 1 \\
SS-3 & $1 / N_{m}$ & $V_{1}$ & 1 & $V_{2} / N_{m}$ & 1 & 1 & 1 & 1 \\
SS-4 & $N_{m}$ & $V_{1} / N_{m}$ & 1 & $V_{2}$ & 1 & 1 & 1 & 1 \\
SS-5 & $1 / N_{m}$ & $V_{1}$ & $1 / N_{m}$ & $V_{2}$ & 1 & 1 & 1 & 1 \\
SS-6 & 1 & $V_{1}$ & $N_{m}$ & $V_{2} / N_{m}$ & 1 & 1 & 1 & 1 \\
\hline PP-1 & 1 & $V_{1}$ & 1 & $V_{2}$ & $N_{m}$ & $N_{m}$ & 1 & 1 \\
PP-2 & 1 & $V_{1}$ & 1 & $V_{2}$ & $N_{m}$ & $N_{m}$ & 1 & $N_{m}$ \\
PP-3 & 1 & $V_{1}$ & 1 & $V_{2}$ & $N_{m}$ & $N_{m}$ & $N_{m}$ & 1 \\
PP-4 & 1 & $V_{1}$ & 1 & $V_{2}$ & 1 & 1 & $1 / N_{m}$ & 1 \\
PP-5 & 1 & $V_{1}$ & 1 & $V_{2}$ & $N_{m}$ & $N_{m}$ & $N_{m}$ & $N_{m}$ \\
PP-6 & 1 & $V_{1}$ & 1 & $V_{2}$ & 1 & 1 & 1 & $1 / N_{m}$
\end{tabular}

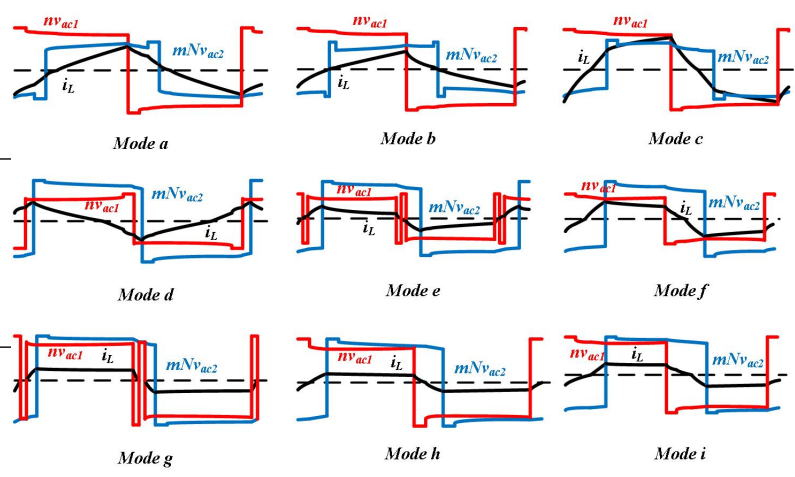

Fig. 8: Waveforms of $n v_{a c 1}, m N v_{a c 2}$ and $i_{L}$ at different operation modes

TABLE II: Operation Conditions for Different Modes

\begin{tabular}{|c|c|}
\hline Mode & Operation Conditions \\
\hline$a$ & $\begin{array}{l}n M a g\left(v_{a c 1}\right)>m N M a g\left(v_{a c 2}\right) \\
i_{L} \text { changes direction after the dead time of output bridges }\end{array}$ \\
\hline$b$ & $\begin{array}{l}n M a g\left(v_{a c 1}\right)>m N M a g\left(v_{a c 2}\right) \\
i_{L} \text { changes direction during the dead time of output bridges }\end{array}$ \\
\hline$c$ & $\begin{array}{l}n M a g\left(v_{a c 1}\right)>m N M a g\left(v_{a c 2}\right) \\
i_{L} \text { changes direction before the dead time of output bridges }\end{array}$ \\
\hline$d$ & $\begin{array}{l}n M a g\left(v_{a c 1}\right)<m N M a g\left(v_{a c 2}\right) \\
i_{L} \text { changes direction before the dead time of input bridges }\end{array}$ \\
\hline$e$ & $\begin{array}{l}n \operatorname{Mag}\left(v_{a c 1}\right)<m N M a g\left(v_{a c 2}\right) \\
i_{L} \text { changes direction during the dead time of input bridges }\end{array}$ \\
\hline$f$ & $\begin{array}{l}n M a g\left(v_{a c 1}\right)<m N M a g\left(v_{a c 2}\right) \\
i_{L} \text { changes direction after the dead time of input bridges }\end{array}$ \\
\hline$g$ & $\begin{array}{l}n M a g\left(v_{a c 1}\right) \approx m N M a g\left(v_{a c 2}\right) \\
i_{L} \text { decreases to zero during the dead time of input bridges }\end{array}$ \\
\hline$h$ & $\begin{array}{l}n M a g\left(v_{a c 1}\right) \approx m N M a g\left(v_{a c 2}\right) \\
i_{L} \text { decreases to zero at the end of the dead time of input bridges }\end{array}$ \\
\hline$i$ & $\begin{array}{l}n M a g\left(v_{a c 1}\right) \approx m N M a g\left(v_{a c 2}\right) \\
i_{L} \text { decreases to zero after the dead time of input bridges }\end{array}$ \\
\hline
\end{tabular}

this paper.

With modeling of the ac link, $i_{L}$ is expressed in time domain. Based on the sequence of switching and the connections of the bridges, the input current and the output current can be expressed in time domain. Finally, the input power $P_{\text {in }}$ (defined as averaged power sourcing from $V_{1}$ ) and the output power $P_{o}$ (defined as averaged power sinking into $V_{2}$ ) can be calculated by averaging the products of the input current and associated dc voltage, respectively. $P_{i n}$ and $P_{o}$ of the DABbased converters with PSM in all of the 9 modes under both of the two power flow directions are given in appendix. Following the derivation of equations for Mode $b$ is given. The derivation of the equations for other modes are similar and are not given in this paper.

Fig. 9 gives the detailed waveforms of $n v_{a c 1}, m N v_{a c 2}$ and $i_{L}$ in Mode b. $T_{d}$ is the dead time of the bridges on both of the

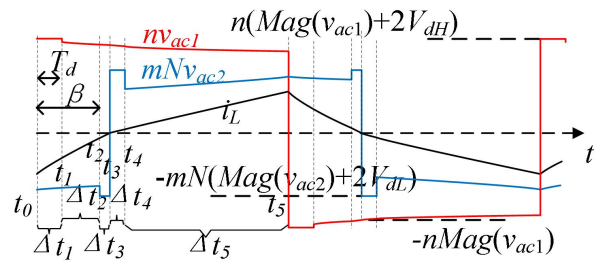

Fig. 9: Detailed waveforms in Mode b

TABLE III: Coefficients $J_{1} \sim J_{5}$ and $M_{1} \sim M_{5}$

\begin{tabular}{l|l|l|l}
\hline$J_{1}$ & $\frac{R_{a c}+2 m N^{2} R_{o n L}}{L_{a c}}$ & $M_{1}$ & $\frac{n\left(M a g\left(v_{a c}\right)+2 V_{d H}\right)+m N M a g\left(v_{a c}\right)}{R_{a c}+2 m N^{2} R_{o n L}}$ \\
\hline$J_{2}$ & $\frac{R_{a c}+2 n R_{o n H}+2 m N^{2} R_{o n L}}{L_{a c}}$ & $M_{2}$ & $\frac{n\left(M a g\left(v_{a c}\right)\right)+m N M a g\left(v_{a c}\right)}{R_{a c}+2 n R_{o n H}+2 m N^{2} R_{o n L}}$ \\
\hline$J_{3}$ & $\frac{R_{a c}+2 n R_{o n H}}{L_{a c}}$ & $M_{3}$ & $\frac{n\left(M a g\left(v_{a c}\right)\right)+m N\left(M a g\left(v_{a c}\right)+2 V_{d L}\right)}{R_{a c}+2 n R_{o n H}}$ \\
\hline$J_{4}$ & $\frac{R_{a c}+2 n R_{o n H}}{L_{a c}}$ & $M_{4}$ & $\frac{n\left(M a g\left(v_{a c}\right)\right)-m N\left(M a g\left(v_{a c} 2\right)+2 V_{d L}\right)}{R_{a c}+2 n R_{o n H}}$ \\
\hline$J_{5}$ & $\frac{R_{a c}+2 n R_{o n H}+2 m N^{2} R_{o n L}}{L_{a c}}$ & $M_{5}$ & $\frac{n\left(M a g\left(v_{a c}\right)\right)-m N M a g\left(v_{a c} 2\right)}{R_{a c}+2 n R_{o n H}+2 m N^{2} R_{o n L}}$ \\
\hline
\end{tabular}

input side and the output side. $\beta$ is the phase shift between the bridges isolated by the ac link. $V_{d H}$ and $V_{d L}$ represent the voltage drop of the switches on the input side and the output side during reverse conduction, respectively. $v_{a c 1}, v_{a c 2}$ and $i_{L}$ in Mode $b$ can then be expressed as follows.

$$
\begin{gathered}
v_{a c 1}(t)= \begin{cases}\operatorname{Mag}\left(v_{a c 1}\right)+2 V_{d H} & t \in\left[t_{0}, t_{1}\right] \\
\operatorname{Mag}\left(v_{a c 1}\right)-2 R_{o n H} i_{L}(t) & t \in\left(t_{1}, t_{5}\right]\end{cases} \\
v_{a c 2}(t)= \begin{cases}-\left(\operatorname{Mag}\left(v_{a c 2}\right)-2 R_{o n L} N i_{L}(t)\right) & t \in\left(t_{0}, t_{2}\right] \\
-\left(\operatorname{Mag}\left(v_{a c 2}\right)+2 V_{d L}\right) & t \in\left(t_{2}, t_{3}\right] \\
\left(\operatorname{Mag}\left(v_{a c 2}\right)+2 V_{d L}\right) & t \in\left(t_{3}, t_{4}\right] \\
\left(\operatorname{Mag}\left(v_{a c 2}\right)+2 R_{o n L} N i_{L}(t)\right) & t \in\left(t_{4}, t_{5}\right]\end{cases} \\
i_{L}(t)= \begin{cases}M_{1}+\left(i_{L}\left(t_{0}\right)-M_{1}\right) e^{-J_{1}\left(t-t_{0}\right)} & t \in\left(t_{0}, t_{1}\right] \\
M_{2}+\left(i_{L}\left(t_{1}\right)-M_{2}\right) e^{-J_{2}\left(t-t_{1}\right)} & t \in\left(t_{1}, t_{2}\right] \\
M_{3}+\left(i_{L}\left(t_{2}\right)-M_{3}\right) e^{-J_{3}\left(t-t_{2}\right)} & t \in\left(t_{2}, t_{3}\right] \\
M_{4}+\left(i_{L}\left(t_{3}\right)-M_{4}\right) e^{-J_{4}\left(t-t_{3}\right)} & t \in\left(t_{3}, t_{4}\right] \\
M_{5}+\left(i_{L}\left(t_{4}\right)-M_{5}\right) e^{-J_{5}\left(t-t_{4}\right)} & t \in\left(t_{4}, t_{5}\right]\end{cases}
\end{gathered}
$$

where $R_{o n H}$ and $R_{o n L}$ are the on-state resistance of the switches on the input side and the output side, respectively. Coefficients $J_{1} \sim J_{5}$ and $M_{1} \sim M_{5}$ are given in Table. III. 
Based on Fig. 9, the following conditions can be set.

$$
\left\{\begin{array}{l}
\Delta t_{1}=T_{d} \\
\Delta t_{2}=\frac{d}{2 f_{s}}-T_{d} \\
t_{4}-t_{2}=T_{d} \\
i_{L}\left(t_{3}\right)=0 \\
t_{5}-t_{0}=\frac{1}{2 f_{s}}
\end{array}\right.
$$

where $f_{s}$ is switching frequency. $d$ is the unified phase shift, whose expression is given as follows.

$$
d=2 \beta f_{s}
$$

At the end of half cycle,

$$
i_{L}\left(t_{5}\right)=-i_{L}\left(t_{0}\right)
$$

Based on (8), $\Delta t_{4}$ can be solved

$\Delta t_{4}=\left(-\frac{1}{J_{3}}\right) \ln \left(\frac{M_{4}+e^{J_{5} \Delta t_{5}}\left(M_{1}\left(1-e^{J_{1} \Delta t_{1}}\right)+M_{5}\left(1-e^{J_{5} \Delta t_{5}}\right)\right.}{+e^{J_{1} \Delta t_{1}}\left(M_{2}+\left(M_{3}-M_{2}\right) e^{J_{2} \Delta t_{2}}\right)}\right)$ With (9), (7) and (3)-(5), $P_{\text {in }}$ and $P_{o}$ can be calculated as.

$$
\begin{gathered}
P_{\text {in }}=2 k_{i n} f_{s} V_{1}\left(I n t_{1}+I n t_{2}+I n t_{3}+I n t_{4}+I n t_{5}\right) \\
P_{o}=2 k_{o} f_{s} V_{2} N\left(-I n t_{1}-I n t_{2}-I n t_{3}+I n t_{4}+I n t_{5}\right)
\end{gathered}
$$

where $\operatorname{Int}_{i}(1 \leq i \leq 5)$ are the averaged $i_{L}$ during interval $\Delta t_{i}$. Int $t_{i}$ for Mode $b$ are expressed as in (12). $k_{\text {in }}$ and $k_{o}$ for different DAB-based converters with PSM are given in Table. I.

$$
\left\{\begin{array}{l}
\text { Int }_{1}=M_{1} \Delta t_{1}+\left(-\frac{1}{J_{1}}\right)\left(i_{L}\left(t_{0}\right)-M_{1}\right)\left(e^{-J_{1} \Delta t_{1}}-1\right) \\
\text { Int }_{2}=M_{2} \Delta t_{2}+\left(-\frac{1}{J_{2}}\right)\left(i_{L}\left(t_{1}\right)-M_{2}\right)\left(e^{-J_{2} \Delta t_{2}}-1\right) \\
\text { Int }_{3}=M_{3} \Delta t_{3}+\left(-\frac{1}{J_{3}}\right)\left(i_{L}\left(t_{2}\right)-M_{3}\right)\left(e^{-J_{3} \Delta t_{3}}-1\right) \\
\text { Int }_{4}=M_{4} \Delta t_{4}+\left(-\frac{1}{J_{4}}\right)\left(i_{L}\left(t_{3}\right)-M_{4}\right)\left(e^{-J_{4} \Delta t_{4}}-1\right) \\
\text { Int }_{5}=M_{5} \Delta t_{5}+\left(-\frac{1}{J_{5}}\right)\left(i_{L}\left(t_{4}\right)-M_{5}\right)\left(e^{-J_{5} \Delta t_{5}}-1\right)
\end{array}\right.
$$

The power flow equations of the rest 8 modes can be derived using the same method and can be found in the appendix of this paper. The calculated power using these equations have been compared against simulations. The derivation of the equations can be guaranteed to be correct [23].

3) Improved Universal Power Flow Model: The above derivation of the universal model uses the same method as the one used to derive DAB-model-1 in [20] and $\mathrm{P}^{2}$ DAB-model-1 in [23]. As mentioned, in [20] and [23], the calculated power does not match with the measurements. Therefore, the basic universal power flow model is expected to have errors unless it is improved. Fig. 10 shows the experimental verification of $\mathrm{P}^{2} \mathrm{DAB}-$ model-1. The maximum error of the predicted output power is $23 \%$. The pattern of error needs to be analyzed in order to identify the cause of the error and then to reduce the error. It can be observed that the mismatch is actually the mismatch between the calculated and measured power plateau [20], where the output and input power remains unchanged.

The pattern of error is summarized as follows. The horizontal mismatch of the ending of the power plateau in time domain is close to the rising time of $v_{a c 1}$. The horizontal

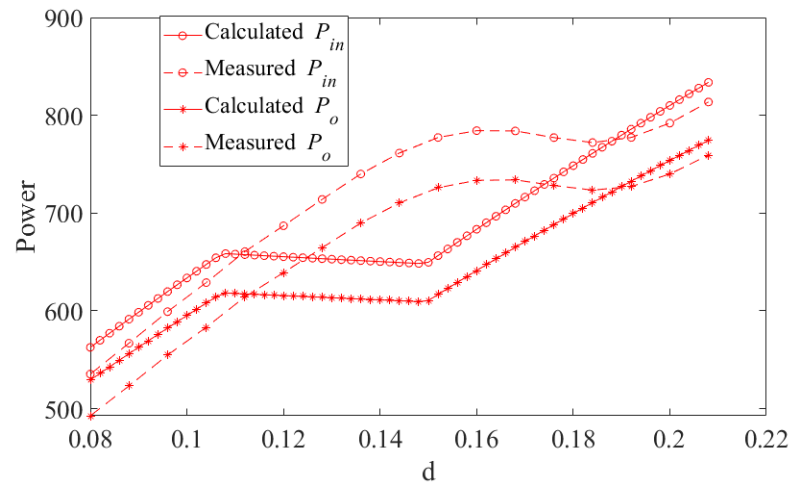

Fig. 10: Measured $P_{\text {in }} \& P_{o}$ vs. $d$ and calculations based on $\mathrm{P}^{2} \mathrm{DAB}-$ model-1@ $V_{1}=300 \mathrm{~V}, V_{2}=25 \mathrm{~V}, T_{d}=70 \mathrm{~ns}$

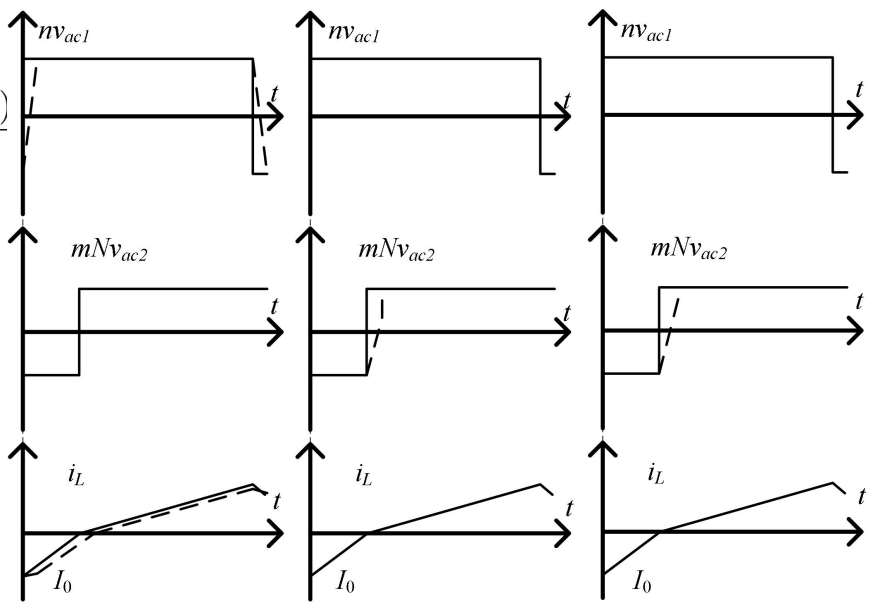

(a)

(b)

(c)

Fig. 11: Influences of resonant commutation on the location and the length of the power plateau. (a) influences of commutation on the input side. (b) influences of commutation (hard-switching) on the output side. (c) influences of commutation (soft-switching) on the output side

mismatch of the starting of the power plateau in time domain is close to the sum of the rising time of $v_{a c 1}$ and the rising time of $v_{a c 2}$. The mismatch of the length of the power plateau is close to the rising time of $v_{a c 2}$. Therefore, it is proposed that the horizontal mismatch between the calculated power and the measured power is due to the finite slew rate of the switching node voltages. In DAB-model-1, $\mathrm{P}^{2} \mathrm{DAB}$-model1 and the basic universal power flow model, the resonant commutation is ignored. The slew rate of the switching node voltages in the models is thereby modeled as infinite.

Fig. 11 gives the typical waveforms, which indicates how the resonant commutations affect the location and the length of the power plateau. The solid lines are the waveforms in ideal cases where the resonant commutation is ignored. The dashed lines are the waveforms in cases where the resonant commutations are considered.

Fig. 11(a) shows that the resonant commutation of the bridge on the input side postpones the zero-crossing of the inductor currents. Therefore, the power plateau's starting, which 
happens when the inductor current and the switching node voltage on the output side reverse directions simultaneously, is postponed.

Fig. 11(b)(c) shows that the resonant commutation of the bridges on the output side postpones the starting of the freewheeling mode and reduces the time during which freewheeling mode occurs. Since the power plateau happens in the free-wheeling mode, the starting of the power plateau is postponed by the rising time of the switching node voltage on the output side; the length of the power plateau is reduced by the same amount in time domain.

The firmest way to verify the analysis on the horizontal mismatch is adding resonant commutation into the universal power flow model, deriving new equations, comparing calculations against measurements. However, this method is not feasible. As shown in Fig. 8, the waveforms of the switching node voltages and the inductor currents have decaying feature, which represents the exponential components in the model. Other than the decaying feature, the only feature left is the perpendicular feature, which represents constants in the model. Because the basic universal power flow model is only consisted by constants and exponents, it has a closed form solution. Once the resonant commutation is considered, new components are added into the model. Depending on how the resonance is modeled, the new components can be linear components or trigonometric components. Consequentially, the model does not have a closed form solution.

Therefore, instead of deriving a new model from scratch, the basic universal model is improved by adjusting the location and the length of the power plateau according to calculated rising time of the switching node voltages. As addressed in [20], the power plateau occurs when the converter operates in Mode $b$. Therefore, improving the basic universal model is based on quantifying the influences of resonant commutations on the boundaries of Mode $b$.

Without considering any lossy elements and dead time, the initial current for the resonant commutation on the input side is calculated by the following equation [23].

$$
I_{0}=-\frac{(2 d-1) m N M a g\left(v_{a c 2}\right)+n M a g\left(v_{a c 1}\right)}{4 f_{s} N^{2} L_{e}}
$$

Without considering the resonant commutation, the time needed for $i_{L}$ to increase from $I_{0}$ to zero can be calculated as:

$$
t_{p \text { ideal }}=\frac{N^{2} L_{e}\left|I_{0}\right|}{n M a g\left(v_{a c 1}\right)+m N M a g\left(v_{a c 2}\right)}
$$

Consider the resonant commutation on the input side and assume that the slew rate of $v_{a c 1}$ is constant, the rising time of $v_{a c 1}$ during commutation $R T_{\mathrm{H}}$ can be calculated as:

$$
R T_{\mathrm{H}}=\frac{2 C_{o s s \mathrm{H}} \operatorname{Mag}\left(v_{a c 1}\right)}{k_{\text {rin }}\left|I_{0}\right|}
$$

where $C_{o s s} \mathrm{H}$ is the output capacitance of the switches in the bridges connected to $V_{1} . k_{\text {rin }}$ can be found in Table. I.

The change of $i_{L}$ during the resonant commutation on the input side can be calculated as:

$$
\Delta I_{\mathrm{RH}}=\frac{R T_{\mathrm{H}} m M a g\left(v_{a c 2}\right)}{N L_{e}}
$$

The time needed for $i_{L}$ to increase from $I_{0}+\Delta I_{R H}$, which is the instant value of $i_{L}$ at the end of the resonant commutation on the input side, to zero can be calculated as:

$$
t_{p \text { real } R T}=\frac{N^{2} L_{e}\left(\left|I_{0}\right|-\Delta I_{\mathrm{RH}}\right)}{n M a g\left(v_{a c 1}\right)+m N M a g\left(v_{a c 2}\right)}
$$

The time needed for $i_{L}$ to increase from $I_{0}$ to zero can thereby be calculated as:

$$
t_{p_{\text {real }}}=R T_{\mathrm{H}}+t_{p_{\text {real }} R T}
$$

delayin, which is defined as the difference between $t_{p}$ ideal and $t_{p \text { real }}$, is used to estimate the horizontal error caused by the resonant commutation on the input side. Following gives the equation of delayin.

$$
\text { delayin }=t_{p \text { ideal }}-t_{p \text { real }}
$$

In order to estimate the horizontal error caused by the resonant commutation on the output side, the rising time of $v_{a c 2}$ during the power plateau needs to be calculated.

At the beginning of the resonant commutation on the output side, $i_{L}$ is zero. Right after the beginning of the resonant commutation, $i_{L}$ changes because the voltage across $L_{e}$ is non-zero. Once $i_{L}$ is non-zero, the output capacitances of the switches on the output side will be charged/discharged. The resonant commutation continues until the output capacitances are fully charged/discharged. Simultaneously, the absolute value of the rate of change of $i_{L}$ reaches its minimum. The following equations are used to model the resonant commutation on the output side during the power plateau.

$$
\begin{gathered}
i_{L}{ }^{k+1}=i_{L}{ }^{k}+\frac{\left(n \operatorname{Mag}\left(v_{a c 1}\right)+m N\left(\operatorname{Mag}\left(v_{a c 2}\right)-2 \Delta V_{r}{ }^{k}\right)\right) t_{s t p}}{N^{2} L_{e}} \\
\Delta V_{r}^{k+1}=\Delta V_{r}{ }^{k}+\left|\frac{k_{r o} N i_{L}{ }^{k+1} t_{s t p}}{2 C_{\text {oss } \mathrm{L}}}\right|
\end{gathered}
$$

where $t_{s t p}$ is the step size used to model the resonant commutation on the output side in time domain. $i_{L}{ }^{k}$ is the instant value of $i_{L}$ at the end of $k^{\text {th }}$ step. $\Delta V_{r}{ }^{k}$ is the absolute value of the change of the drain-to-source voltage of one of the switches on the output side at the end of the $k^{\text {th }}$ step compared to the initial value of the current step. $C_{o s s \mathrm{~L}}$ is the output capacitance of the switches in the bridges connected to $V_{2} . k_{r o}$ can be found in Table. I.

The rising time of the switching node voltage on the output side $R T_{\mathrm{L}}$ can be calculated as:

$$
R T_{\mathrm{L}}=N_{s t p} t_{s t p}
$$

where $N_{s t p}$ is the number of time steps after which $\Delta V_{r}$ reaches $\operatorname{Mag}\left(v_{a c 2}\right)$.

With the above modeling of resonant commutations, the horizontal errors can be mitigated. The calculated starting of the power plateau based on the basic universal model should be 
postponed by the sum of delayin and $R T_{\mathrm{L}}$, while the calculated ending of the power plateau should be postponed by delayin.

Adjusting the power plateau horizontally is basically moving the power plateau left or right, which could make the $P_{\text {in }} \&$ $P_{o}$ vs. $d$ curves discontinued. Therefore, vertical compensation are needed to rebuild the $P_{\text {in }} \& P_{o} v s$. $d$ curves.

The equation below gives the power flow of the DAB-based converters with PSM in the ideal case, i.e. without considering any losses nor dead time.

$$
P_{\text {in }}=P_{o}=\frac{V_{1} k_{\text {in }} m M a g\left(v_{a c 2}\right) d(1-d)}{2 f_{s} N L_{e}}
$$

The second order derivative of $P_{\text {in }} \& P_{o}$ to $d$ in the ideal case is:

$$
\operatorname{Deri}_{2}=P_{i n}{ }^{(2)}=P_{o}^{(2)}=-\frac{V_{1} k_{i n} m M a g\left(v_{a c 2}\right)}{f_{s} N L_{e}}
$$

which is a constant. Deri 2 represents the second order derivative of $P_{i n} \& P_{o}$ to $d$ in the ideal case. $d_{s t p}$ is the step size of unified phase shift $d . P_{j}$ represents the input/output power at $j^{\text {th }}$ step of $d$.

Using the finite difference method, the first order derivative of $P_{j}$ and $P_{j-1}$ can be approximated as:

$$
\begin{gathered}
P_{j}^{(1)}=\frac{P_{j+1}-P_{j}}{d_{s t p}} \\
P_{j-1}^{(1)}=\frac{P_{j}-P_{j-1}}{d_{s t p}}
\end{gathered}
$$

The second order derivative of $P_{\text {in }} \& P_{o}$ to $d$ in the ideal case can be expressed by:

$$
\operatorname{Deri}_{2}=\frac{P_{j}^{(1)}-P_{j-1}^{(1)}}{d_{s t p}}
$$

Therefore, the relationship among $P_{j-1}$ and $P_{j}, P_{j+1}$ can be expressed as:

$$
P_{j+1}=2 P_{j}-P_{j-1}+d_{s t p}^{2} \text { Deri }_{2}
$$

By using (28), the continuity of $P_{i n} \& P_{o} v s . d$ curves is guaranteed.

4) Simulation App and Code Sharing: As can be seen from the derivation, the improved universal power flow model is complicated, and is hard for readers to apply from scratch. Therefore, the model has been packaged as a simulation app 'PowerDAB', whose screen shot is shown in Fig. 12. 'PowerDAB' and the model's equations written in MATLAB script is available under an open source license [25]. Readers only need to download them. 'PowerDAB' can be easily used to do basic calculation of the power flow of DAB-based converters with phase shift modulation. The model's script can be used as blocks in other optimization algorithms for a wide variety of design purposes. The authors would like to keep upgrading 'PowerDAB' by adding in optimization functions for different design objectives. Please write to the authors if you found bugs or you would like to propose nice-to-have functions for 'PowerDAB'.

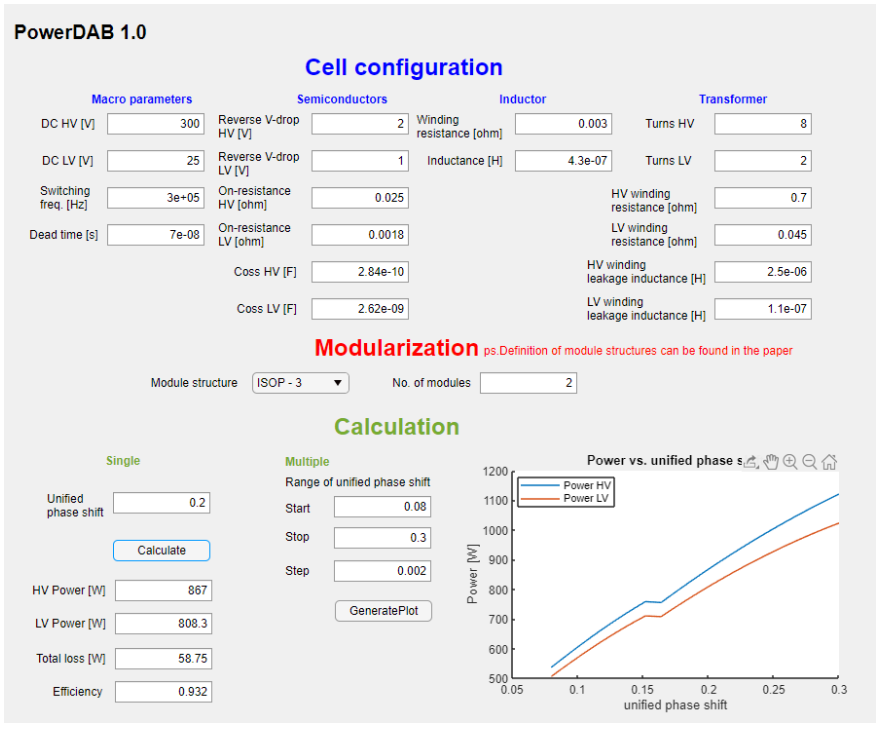

Fig. 12: Screen shot of 'PowerDAB'

TABLE IV: Parameters used in the analysis based on $\mathrm{P}^{2} \mathrm{DAB}-$ Model-2

\begin{tabular}{l|l|l|l}
\hline$V_{d H}(\mathrm{~V})$ & 2 & $V_{d L}(\mathrm{~V})$ & 1 \\
\hline$R_{o n H}(\mathrm{~m} \Omega)$ & 25 & $R_{o n L}(\mathrm{~m} \Omega)$ & 1.8 \\
\hline$R_{t r p}(\Omega)$ & 0.7 & $R_{t r s}(\mathrm{~m} \Omega)$ & 45 \\
\hline$L_{t r p}(\mu \mathrm{H})$ & 2.5 & $L_{t r s}(\mathrm{nH})$ & 110 \\
\hline$f_{s}(\mathrm{kHz})$ & 300 & $N_{m}$ & 2 \\
\hline$R_{e}(\mathrm{~m} \Omega)$ & 3 & $L_{e}(\mathrm{nH})$ & 430 \\
\hline$V_{1}(\mathrm{~V})$ & 180 & $V_{2}(\mathrm{~V})$ & 15 \\
\hline$N$ & 4 & $C_{o s s}(\mathrm{pF})$ & 284 \\
\hline$C_{\text {oss }}(\mathrm{pF})$ & 2620 & $T_{d}(\mathrm{~ns})$ & 70 \\
\hline
\end{tabular}

\section{Case Study: Apply the Improved Universal POWER Flow MOdel to THE $\mathrm{P}^{2}$ DAB CONVERTER With PSM}

In this section, as a case study, the derived improved universal power flow model is applied to the $\mathrm{P}^{2} \mathrm{DAB}$ Converter with PSM. The power plateau phenomenon, the anti-power phenomenon and the efficient power plateau are analyzed in detail based on the generated model.

\section{A. Generate P $P^{2} D A B$-Model-2}

$\mathrm{P}^{2} \mathrm{DAB}-$ Model-2 for the $\mathrm{P}^{2} \mathrm{DAB}$ Converter with PSM is generated based on the improved universal power flow model derived in the last section. The parameters used in $\mathrm{P}^{2} \mathrm{DAB}-$ Model-2 are given in Table. IV. These parameters are extracted from the $\mathrm{P}^{2} \mathrm{DAB}$ prototype used in the experiments.

As mentioned, the method used to derive the basic universal power flow model is same as the one used to derive $\mathrm{P}^{2} \mathrm{DAB}-$ Model-1. As shown Fig. 10, except in the ranges of $d$ where the power plateau happens, $\mathrm{P}^{2} \mathrm{DAB}-$ Model-1 is able to precisely predict both $P_{\text {in }} \& P_{o}$ before and after the power plateau. The improved universal power flow model is based on the basic power flow model, while additionally takes the resonant commutation of the bridges into account in order to have precise prediction of the power plateau. $\mathrm{P}^{2} \mathrm{DAB}-$ Model-2, which is generated from the improved power flow model, will 
inherit the capabilities of $\mathrm{P}^{2} \mathrm{DAB}-$ Model-1, i.e. capabilities of precisely predicting both $P_{\text {in }} \& P_{o}$ before and after the power plateau. Therefore, the model-based analysis in this paper will focus on the power flow characteristics related to the power plateau, which happens in Mode $b$. Please refer to $\mathrm{P}^{2} \mathrm{DAB}$ Model-1 in [23] for the $P_{i n} \& P_{o} v s . d$ characteristics of the other 8 modes, i.e. Mode $a$ and Mode $c$ - Mode $i$, at both of the power flow directions.

\section{B. Power Plateau Phenomenon}

The power plateau phenomenon appears when the $\mathrm{P}^{2} \mathrm{DAB}$ converter operates in Mode $b$, whose waveforms are shown in Fig. 9. In this mode, $i_{L}$ changes polarity during the dead time of the lagging bridges. The switches of the lagging bridges are thereby in natural commutation. Resultantly, $i_{L}$ becomes in-phase with $m N v_{a c 2}$. As derived in (11) and (12), the power flow through ac link is determined by the averaged product of $i_{L}$ and $m N v_{a c 2}$. Since $i_{L}$ is in-phase with $m N v_{a c 2}$, the power flow could only be altered by changing the shape of $i_{L}$ and $m N v_{a c 2}$. The effects of the shapes of $i_{L}$ and $m N v_{a c 2}$ on the power flow is weaker than that of the phase shift between $i_{L}$ and $m N v_{a c 2}$. Therefore, the power could not be altered in Mode $b$. This phenomenon of unadjustable power is called the power plateau phenomenon.

Based on $\mathrm{P}^{2} \mathrm{DAB}-$ Model-2, calculations are done to investigate the impacts of circuit parameters on the power plateau's length i. e. range of $d$ where the plateau occurs, and the power plateau's location i. e. $d$ where the power plateau starts and ends. The circuit parameters considered in $\mathrm{P}^{2} \mathrm{DAB}-$ Model-2 has been listed in Table. IV. Studying the influences of all of the listed parameters is unnecessary. $R_{o n H}, R_{o n L}, V_{d H}$ and $V_{d L}$ would be fixed once the switches are selected. $N, R_{t r p}, R_{t r s}, R_{e}$, $L_{t r p}, L_{t r s}$, and $L_{e}$ wound be fixed once the transformers and the inductors are wound. Therefore, influences of $R_{o n H}, R_{o n L}, V_{d H}$, $V_{d L}, N, R_{t r p}, R_{t r s}, R_{e}, L_{t r p}, L_{t r s}$, and $L_{e}$ on the power plateau are not investigated. In PSM, $f_{s}$ is fixed. $N_{m}$ has no impacts on differentiating the 9 modes shown in Fig. 8. Therefore, the influences of $f_{s}$ and $N_{m}$ are not studied. Influences of $V_{1}$ and $V_{2}$ would be given in the next subsection as they trigger anther so-called anti-power phenomenon. To summarize, only the influences of $T_{d}, C_{o s s H}$ and $C_{o s s L}$ on the power plateau is investigated in this subsection.

It is found that $T_{d}, C_{o s s H}$ and $C_{\text {oss }}$ are the key parameters that have influences on the power plateau under both $V_{1} \rightarrow V_{2}$ and $V_{2} \rightarrow V_{1}$.

Under $V_{1} \rightarrow V_{2}$ :

- When $T_{d}$ is increased, the length of the power plateau increases; $d$ where the power plateau starts decreases; $d$ where the power plateau ends keeps unchanged.

- When $C_{o s s L}$ is increased, the length of the power plateau decreases; $d$ where the power plateau starts increases; $d$ where the power plateau ends keeps unchanged.

- When $C_{\text {ossL }}$ is increased to a value with which the commutation of the lagging bridge cound not be completed within $T_{d}$, the power plateau disappears.

- When $C_{o s s H}$ is increased, the length of the power plateau keeps unchanged; $d$ where the power plateau starts increases; $d$ where the power plateau ends increases.

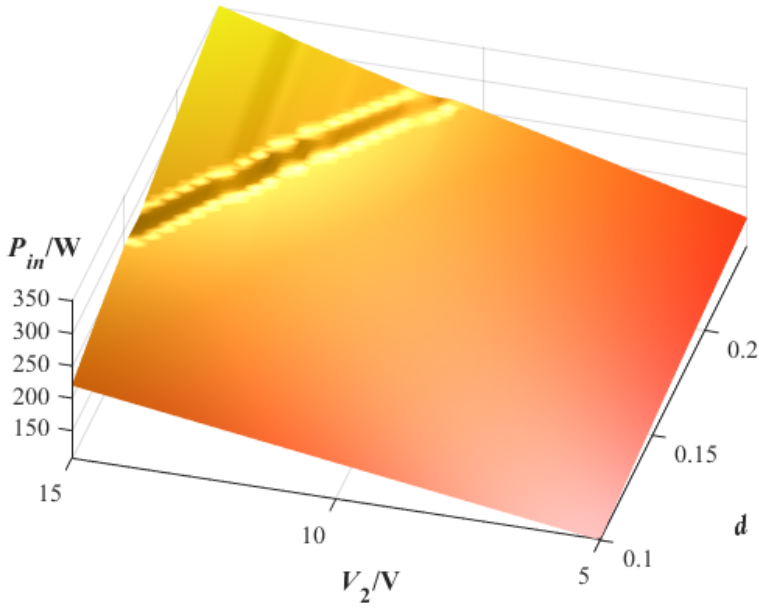

Fig. 13: Calculated anti-power phenomenon using P2DAB-Model-2 with parameters in Table. IV @ $V_{1} \rightarrow V_{2}$

Under $V_{2} \rightarrow V_{1}$ :

- The influence of $T_{d}$ on the power plateau is same to that under $V_{1} \rightarrow V_{2}$.

- The influence of $C_{o s s H}$ on the power plateau is same to the influence of $C_{\text {oss } L}$ under $V_{1} \rightarrow V_{2}$.

- The influence of $C_{\text {oss } L}$ on the power plateau is same to the influence of $C_{o s s H}$ under $V_{1} \rightarrow V_{2}$.

\section{Influences of Power Plateau Phenomenon}

As discussed in the last subsection, the power flow can not be adjusted during the power plateau. If an adjustable power flow is required, the power plateau should be avoided. Ideally, in order to do this, the designer could either carefully select $T_{d}, C_{o s s H}$ and $C_{o s s L}$ so that the length of the power plateau is zero, i.e. the power plateau disappears; or make sure that the converter does not operate in Mode $b$, where the power plateau happens. However, avoiding the power plateau could be difficult in applications where the load and the input/output voltage have wide ranges. Because the converter could operate in Mode $b$ when the load and input/output voltage range are wide. Given that the location and the length of the power plateau also depend on load and input \& output voltage (as indicated in (13)-(22), which have $\operatorname{Mag}\left(v_{a c 1}\right), \operatorname{Mag}\left(v_{a c 2}\right)$, or $I_{0}$ on the right side of the equations explicitly or implicitly), eliminating the power plateau would at least require the following two implementations in control: (1) check if the converter operates in Mode $b$. (2) adjustment of $T_{d}$ to ensure it equals to $R T_{L}$, so that the length of the power plateau is zero in Mode $b$. However, as will be shown in the experiments, $\mathrm{P}^{2} \mathrm{DAB}-M o d e l-2$ and the calculation of $R T_{L}$ still have errors. Neither of the two implementations would be easy. Since the power plateau would most likely appear in DAB-based converters with wide load and input/output voltage ranges, analysis on the influences of the power plateau phenomenon is necessary.

1) Anti-power phenomenon: The power plateau causes the anti-power phenomenon. Please note that the plots in this 


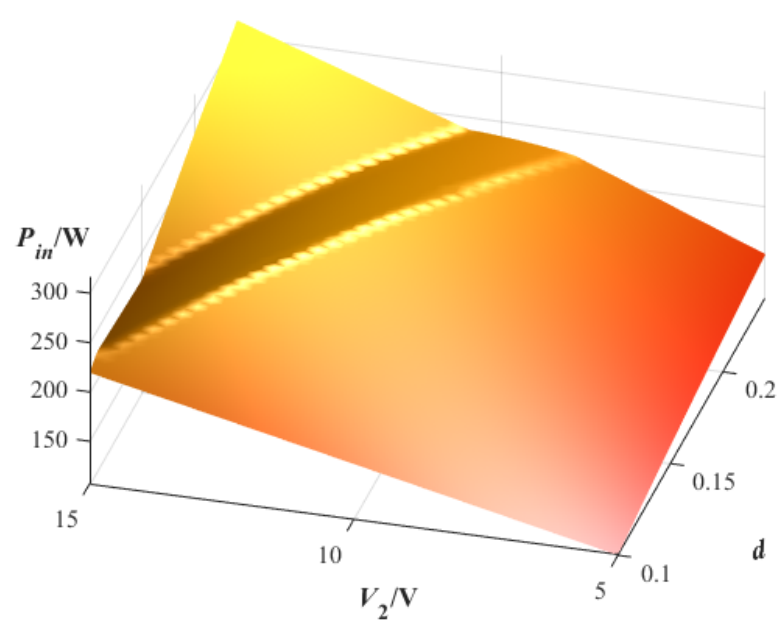

Fig. 14: Calculated anti-power phenomenon using $\mathrm{P}^{2} \mathrm{DAB}-M o d e l-1$ with parameters in Table. IV @ $V_{1} \rightarrow V_{2}$

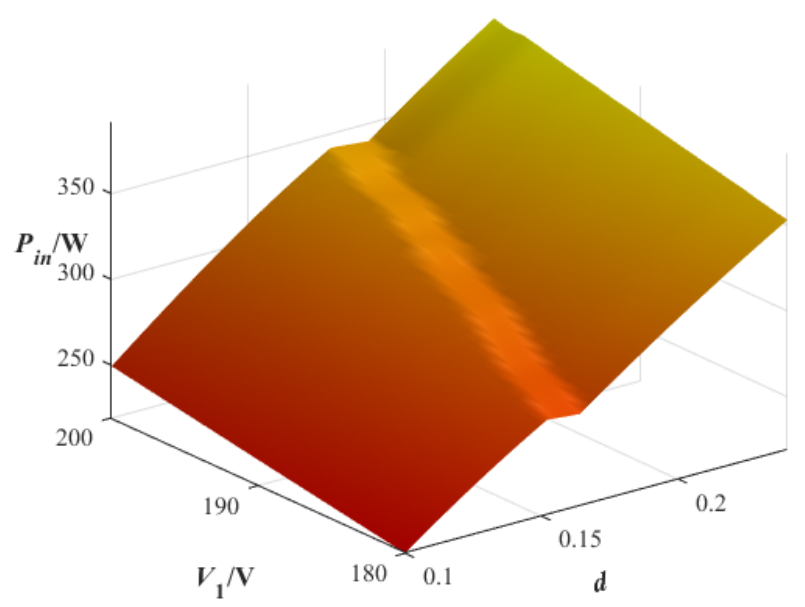

Fig. 15: Calculated influences of $V_{1}$ on the power plateau using P2DAB-Model-2 with parameters in Table. IV @

$$
V_{1} \rightarrow V_{2}
$$

subsection only show $P_{\text {in }}$ since $P_{o}$ has the same pattern as $P_{i n}$. Fig. 13 shows the calculated anti-power phenomenon under $V_{1} \rightarrow V_{2}$ by substituting parameters in Table. IV (except $V_{2}$, which is a variable in this plot) into $\mathrm{P}^{2} \mathrm{DAB}-$ Model-2. As shown, at certain ranges of $d, P_{i n}$ no longer increases (or decreases) with increasing (or decreasing) $V_{2}$.

Fig. 13 also shows the influences of $V_{2}$ on the power plateau. Changing $V_{2}$ does not change the length of the power plateau. However, increasing $V_{2}$ would decrease the $d$ where the power plateau starts (and ends). Fig. 14 shows the plot of anti-power phenomenon calculated by $\mathrm{P}^{2}$ DAB-Model-1, which can be generated by the basic universal model. Since the resonant commutation of the bridges is ignored in $\mathrm{P}^{2} \mathrm{DAB}-$ Model-1, the length of the power plateau in Fig. 14 is longer than that in Fig. 13; the power plateau in Fig. 14 starts at smaller $d$ than that in Fig. 13. Other than the difference in predicting the location and the length of the power plateau,
$\mathrm{P}^{2} \mathrm{DAB}-M o d e l-1$ is able to predict the basic pattern of the power plateau and the anti-power phenomenon.

Fig. 15 shows the influences of $V_{1}$ on the power plateau by substituting parameters in Table. IV (except $V_{2}$, which is a variable in this plot) into $\mathrm{P}^{2} \mathrm{DAB}-M o d e l-2$. As shown, Changing $V_{1}$ does not change the length of the power plateau. However, decreasing $V_{1}$ would decrease the $d$ where the power plateau starts (and ends).

The anti-power phenomenon and the influences of $V_{1} \& V_{2}$ on the power plateau under $V_{2} \rightarrow V_{1}$ is also analyzed based on $\mathrm{P}^{2}$ DAB-Model-2. The conclusions are summarized as follows. When $m N M a g\left(v_{a c 2}\right)>n M a g\left(v_{a c 1}\right)$ :

- At certain ranges of $d$, which can be calculated by $\mathrm{P}^{2}$ DAB-Model-2, $P_{\text {in }} \& P_{o}$ no longer increases (or decreases) with increasing (or decreasing) $V_{1}$.

- Neither $V_{1}$ nor $V_{2}$ affect the length of the power plateau.

- Increasing $V_{1}$ would decrease the $d$ where the power plateau starts (and ends), and vice versa.

- Decreasing $V_{2}$ would decrease the $d$ where the power plateau starts (and ends), and vice versa.

2) Influences on maximum and minimum power transfer: The power plateau does not affect the maximum power transfer. When the power transfer is near maximum, the phase shift in time domain is much larger than $T_{d}, R T_{H}$ and $R T_{L}$. Therefore, when changes are made in either $T_{d}, R T_{H}$ or $R T_{L}$, the length and the location of the power plateau will change; while the maximum power transfer, which is dominated by the large phase shift, will not change. However, either $T_{d}, R T_{H}$ or $R T_{L}$ will affect the power transfer at low power ranges. Because when the power transfer is low, the phase shift in time domain is comparable to $T_{d}, R T_{H}$ and $R T_{L}$.

The minimum power transfer increases with the length of the power plateau. Due to the free-wheeling operation during the power plateau, the actual phase shift angle between $v_{a c 1}$ and $v_{a c 2}$ is larger than the one between gate signals, e.g. $\mathrm{G}_{1}$ and $\mathrm{G}_{5}$. The longer the power plateau, the larger the mismatch between the actual phase shift angle and the set one, and hence, the larger the minimum power transfer. The increased minimum power transfer could also be explained as: given that the power transfer at large $d$ is fixed, and that generally the power decreases with $d$, the power transfer at $d=0$ will be boosted up once defining that the power remains unchanged when $d$ is within certain ranges. And the larger the range of $d$ where the power remains unchanged, the larger the minimum power transfer.

3) Influences on close-loop stability and bandwidth: On the power plateau, the power flow inversely reacts to the perturbations in $d$. It is thereby interesting to investigate the influences of the power plateau on the dynamic performance of DAB based converters with close loop control. As part of preliminary works, simulations are done in PSIM to study the power plateau's influences on the stability and the bandwidth of the $\mathrm{P}^{2} \mathrm{DAB}$ converter with single current loop closed. The diagram of simulation is presented in Fig. 16. The control scheme aims at regulating the averaged output current $I_{f}$ to make it follow $I_{\text {ref }}$, which is the control reference. Since the output of the converter is connected to a DC voltage source, the control scheme actually regulates the power flow of the 


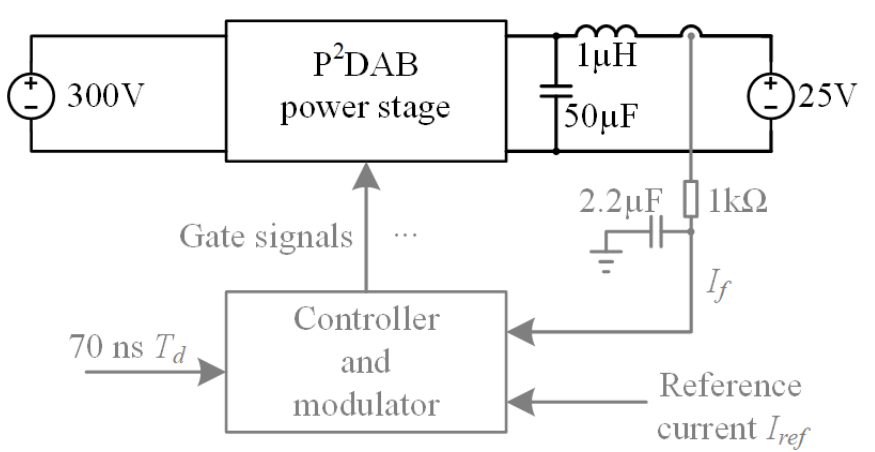

Fig. 16: Diagram of simulation in PSIM to study power plateau's influences on close-loop control

$\mathrm{P}^{2} \mathrm{DAB}$ converter. In order to speed up simulation, the $\mathrm{P}^{2} \mathrm{DAB}$ power stage uses ideal components. Without considering any parasitic nor lossy elements, the power plateau starts at $d=0.13$, ends at $d=0.17$. The output current during the power plateau operation is $25.2 \mathrm{~A}$, corresponding to a power flow of $630 \mathrm{~W}$.

Fig. 17 shows the simulated $I_{r e f}$ to $I_{f}$ bode plot under different DC bias of $I_{\text {ref }}$. The DC bias of $I_{\text {ref }}$ is swept from 23A to $28 \mathrm{~A}$ with step size of $0.1 \mathrm{~A}$. The magnitude of perturbations is $1 \%$ of DC bias. $f_{p}$ is the perturbation frequency. As marked in Fig. 17, 'Front of low power' is the cluster of bode plots at $I_{\text {ref }}$ of 23A-24A. 'Front of high power' is the cluster of bode plots at $I_{r e f}$ of $27 \mathrm{~A}-28 \mathrm{~A}$. Bode plots draw with dashed lines are those at $I_{r e f}$ of $25 \mathrm{~A}-27 \mathrm{~A}$. Bode plots at $I_{r e f}$ of 24A-25A are between the 'Front of low power' and the 'Front of high power'. They are not shown in Fig. 17 in order to make the plot neat. As shown by the pink transparent arrows, when $I_{\text {ref }}$ is swept from 23A to 28A, the bode plots will shift left from the 'Front of low power', gradually towards the dashed plots until it reaches the most left and the most fluctuated, then gradually shift back towards the 'Front of high power'.

As shown in Fig. 17, at both high power and low power operation, the system has over $45^{\circ}$ phase margin, and is able to follow perturbations up to $750 \mathrm{~Hz}$. However, when the converter runs into power plateau, both the phase margin and the bandwidth are decreased. The converter thereby becomes less stable and reacts slowly to control reference.

The influences of the power plateau on close-loop control might vary with control strategies. The analysis given above is only an example which might be representative. Comprehensive analysis and experimental verification are needed in order to make firm conclusions on this topic. This could be part of the future work.

4) Influences on model-based predictive control: Modelbased predictive controls (MPC) on the DAB converter have been gaining attentions because of their capability of enhancing the converters' dynamic performance [26]- [29]. Generally, MPC strategies for the DAB converters include: the loadcurrent feed forward scheme, the direct-inductance-current control strategy and the power-based control method [29]. In applications where quickly reaching the desired output power is the prior requirement of dynamic control, the powerbased control method is a promising alternative [27]. Since potentially the derived universal power flow model can be used

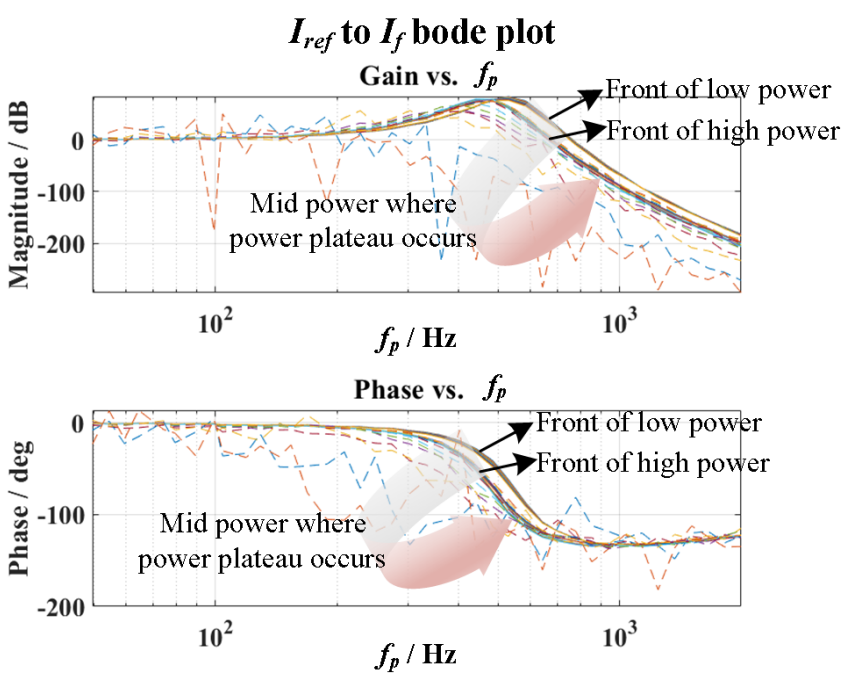

Fig. 17: $I_{r e f}$ to $I_{f}$ bode plot

in MPC, the possible advantages and drawbacks of using the derived model in MPC compared to state-of-the-art powerbased control method for the DAB converter need to be discussed. The virtual-direct-power control (VDPC) proposed in [27] for the DAB converter is selected as the reference to which the comparison is made.

In the VDPC scheme, a mathematical model is used to calculate the phase shift angle with which the desired output power can be reached immediately. The experimental results show that, with the VDPC scheme, excellent dynamic behaviors can be obtained when the load and the input voltage are suddenly changed. The mathematical model used in VDPC takes the input voltage, the output current, the desired output voltage, and the output of the PI controller of the voltage loop as inputs. Therefore, the VDPC scheme is not sensitive to circuit parameters such as the ac inductance, on-resistance of the switches, or the leakage inductance of the transformer. The equations used in the mathematical model are not complicated. Therefore, it should not be too difficult to implement the VDPC scheme in digital controllers. However, the VDPC scheme requires accurate measurement of the load current within one switching period. This kind of measurement can be difficult when the DAB converter is connected to other converters with output capacitors placed parallel in between [29].

Compared to the power estimation model used in the VDPC scheme, the derived universal power flow model does not require accurate measurement of the load current, it only requires sensing of input and output voltage. However, the derived model is too complicated to be directly implemented in digital controllers as it has many variables and many exponential calculations and divisions, which take much longer to execute than additions and subtractions. Also in consequence of considering many parameters, which might drift when the converter operates, the model's sensitivity to these circuit parameters needs to be analyzed.

$L_{\text {trp }}, L_{\text {trs }}$ and $L_{e}$ are the inductive elements along the ac 


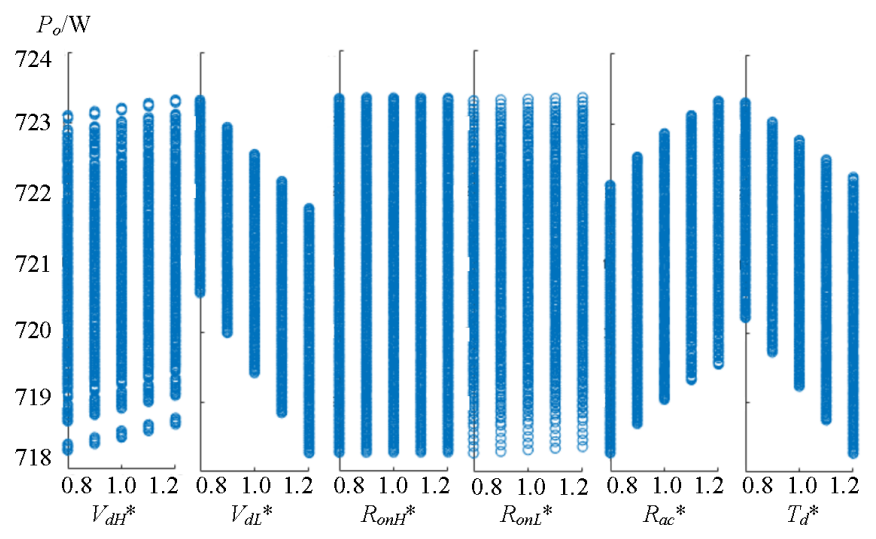

Fig. 18: $\mathrm{P}^{2} \mathrm{DAB}-M o d e l-2$ 's sensitivity in Mode $c$ to $R_{a c}, T_{d}$, $R_{o n H}, R_{o n L}, V_{d H}$ and $V_{d L}$

link. The sum of the three determines the power level of the converter. The model is thereby sensitive to $L_{t r p}, L_{t r s}$ and $L_{e}$. $C_{\text {ossH }}$ and $C_{\text {ossL }}$ are used in the calculation of power in Mode $b$. And they are the key parameters that affect the characteristics of the power plateau. Therefore, the model is sensitive to $C_{o s s}$ and $C_{\text {ossL }}$. Fig. 18, which is a scatter plot of $P_{o}$ at $d=0.2$ under different $R_{a c}, T_{d}, R_{o n H}, R_{o n L}, V_{d H}$ and $V_{d L}$, shows the model's sensitivity in Mode $c$ to to these parameters. The x-axis, i.e. $R_{a c}{ }^{*}, T_{d}{ }^{*}, R_{o n H}{ }^{*}, R_{o n L}{ }^{*}, V_{d H}{ }^{*}$ and $V_{d L}{ }^{*}$, are the nominal values of $R_{a c}, T_{d}, R_{o n H}, R_{o n L}, V_{d H}$ and $V_{d L}$ in respect to the values listed in Table. IV. As shown, the model is at least sensitive to $R_{a c}, T_{d}, V_{d H}$ and $V_{d L}$. The model looks less sensitive to $R_{o n H}$ and $R_{o n L}$ than to other parameters in Fig. 18. This is because the losses due to the on-resistance of the switches are small with the parameters in Table. IV. In cases where the losses due to the on-resistance of the switches dominate, the model would behave as being sensitive to $R_{o n H}$ and $R_{o n L}$. Therefore, to summarize, the derived model is sensitive to all of the considered parameters. High sensitivity to parameters that are difficult to the detected online is a bad feature for models used in MPC. However, it is a good feature for models used in static design and optimization.

Since the derived model is complex and sensitive to parameters that could hardly be detected online, it cannot be directly used in MPC. However, it could offer suggestions to existing MPC to tackle with the power plateau, and hence, possibly improve the dynamic behavior further. For example, given that the VDPC scheme has already been able to detect the output power, it could be helpful to save and compare the detected output power of adjacent control steps. By doing so the controller can estimate if the converter was operating on power plateau, and then decide to directly jump out of the power plateau or not. Jumping across or staying on the power plateau could be done by changing the control variable according to lookup tables, which are pre-calculated offline by using the derived universal power flow model.

\section{Efficient Power Plateau}

Since $i_{L}$ is in-phase with $m N v_{a c 2}$ in Mode $b$, there is no reactive power flow in the lagging bridge, which helps to

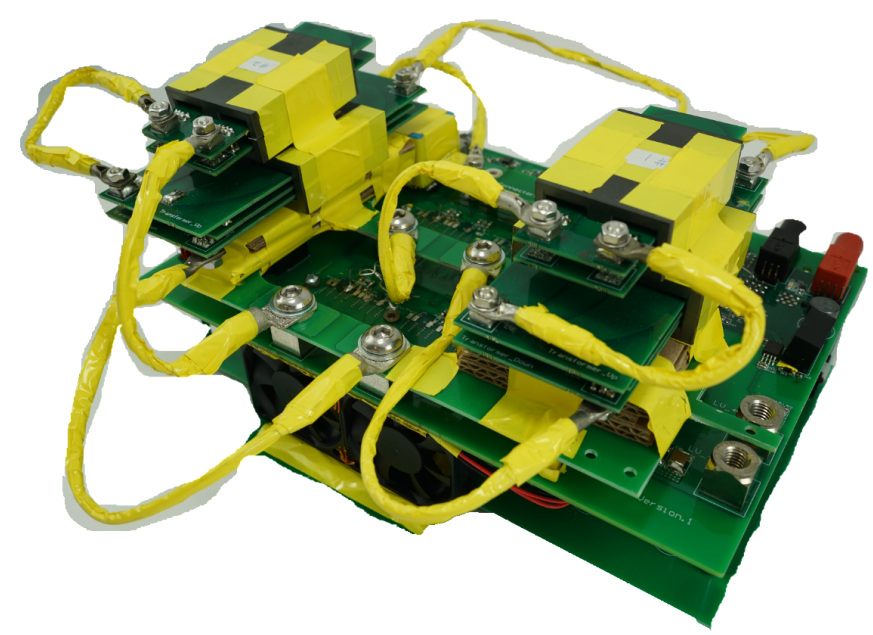

Fig. 19: Picture of the $\mathrm{P}^{2} \mathrm{DAB}$ prototype

TABLE V: Specifications of the $\mathrm{P}^{2} \mathrm{DAB}$ prototype

\begin{tabular}{l|l}
\hline Parameters & values \\
\hline$V_{1}, V_{2}$ & $400 \mathrm{~V}, 40 \mathrm{~V}$ \\
maximum $P_{o}$ & $1.7 \mathrm{~kW}$ \\
switches on high voltage side & GS66516B \\
switches on low voltage side & EPC2021 \\
transformer & $8: 2$, Ferrite N97, ELP64 \\
inductor & $430 \mathrm{nH}$, Ferrite N97, 2 ELP43 in stack \\
switching frequency & $300 \mathrm{kHz}$ \\
\hline
\end{tabular}

reduce coduction losses.

Regarding the switching losses, due to the free-wheeling mode operation during the power plateau, the zero voltage turn on of all the switches is ensured. And because of the natural commutation between the two body diodes during the power plateau, the switch expected to be turned off achieves zero current turn off, while the switch expected to be turned on achieves zero current turn on.

Therefore, a hypothesis is made: During the power plateau operation, the $\mathrm{P}^{2} \mathrm{DAB}$ converter should be more efficient than other operation modes.

\section{E. Model-based Static Optimizations}

The $\mathrm{P}^{2} \mathrm{DAB}-\mathrm{Model}-2$ is only a power flow model. However, its derivation brings more than a $\mathrm{P}^{2} \mathrm{DAB}-M o d e l-2$. The timedomain expression of the input \& output current, the current flowing through the switches, the inductor current and the voltage across the transformers' windings are all obtained. These models can all be used for static optimization of the $\mathrm{P}^{2} \mathrm{DAB}$ converter and its components.

\section{EXPERIMENTS}

A $P^{2} \mathrm{DAB}$ prototype using Gallium Nitride $(\mathrm{GaN})$ devices is built to verify the analysis. Fig. 19 gives a picture of the prototype. The specifications of the prototype and the components used in the prototype are listed in Table. V. $V_{1}$ $\& V_{2}$ and $P_{\text {in }} \& P_{o}$ are measured by N4L PPA5530 power analyzer. 


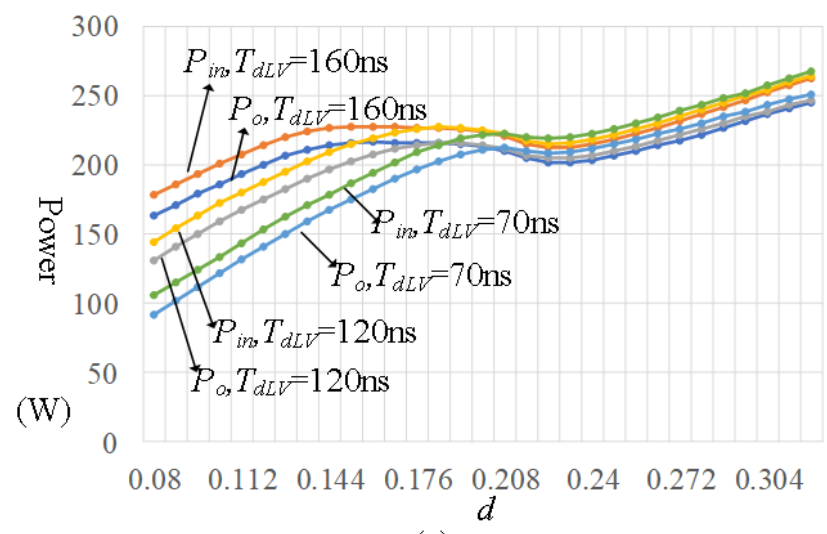

(a)

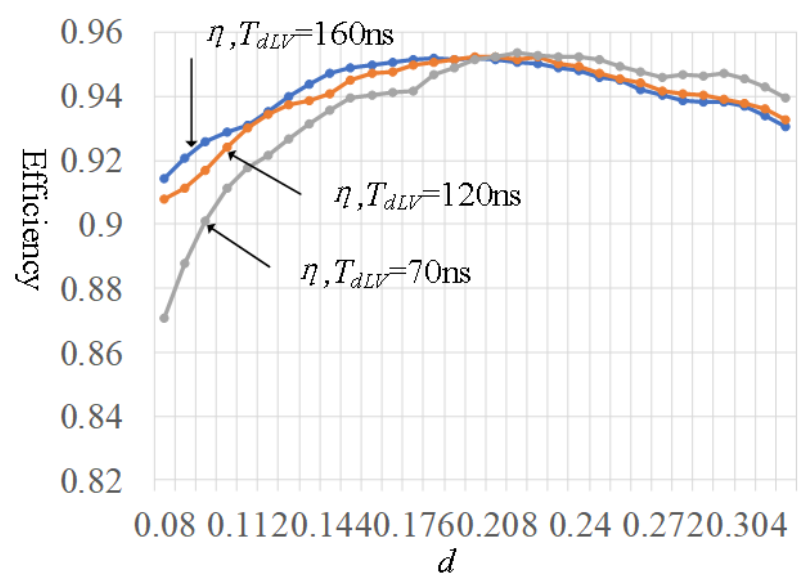

(b)

Fig. 20: Measured $P_{\text {in }} \& P_{o} \&$ efficiency vs. $d$ under different $T_{d L V} @ V_{1}=180 \mathrm{~V}, V_{2}=15 \mathrm{~V}$

A. Verification of the Power Plateau Phenomenon, the Antipower Phenomenon, and the Efficient Power Plateau

$T_{d H V}$, which is the dead time of the bridges connected to $V_{1}$, is fixed to be 206ns. Fig. 20 gives the measured $P_{\text {in }} \&$ $P_{o} \&$ efficiency $\eta v s . d$ under different $T_{d L V}$, which is the dead time of the bridges connected to $V_{2} . V_{1}$ is connected to a dc voltage source DELTA ELEKTRONIKA SM 600-10 and is setd to 180VDC. $V_{2}$ is connected to a dc electric load Chroma 63204A-600-280 and is set to 15VDC.

As shown in Fig. 20(a), under different $T_{d L V}$ (160ns, 120ns and 70ns), the measured $P_{\text {in }} \& P_{o}$ decreases in specific ranges of $d$. Therefore, the power plateau does exist in the $\mathrm{P}^{2} \mathrm{DAB}$ converter. When $T_{d L V}$ is increased, the length of the power plateau increases; the $d$ where the power plateau starts decreases, the $d$ where the power plateau ends keeps unchanged, which matches the analyses in Section III. As could be observed, when the length of the power plateau increases, the maximum power transfer remains unchanged, the minimum power transfer increases, which matches with the analysis about the influences of the power plateau on maximum \& minimum power transfer in Section III. Fig. 20(b) gives the measured efficiency of the $\mathrm{P}^{2} \mathrm{DAB}$ prototype. As shown, the efficiency of the prototype is higher during

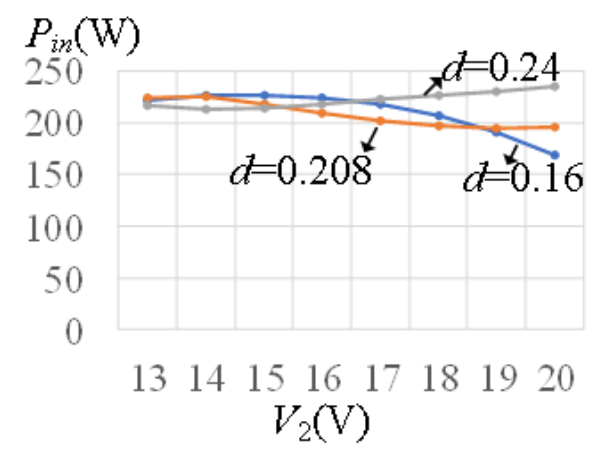

Fig. 21: Measured anti-power phenomenon@ $V_{1} \rightarrow V_{2}$, $V_{1}=180 \mathrm{~V}, T_{d L V}=160 \mathrm{~ns}$

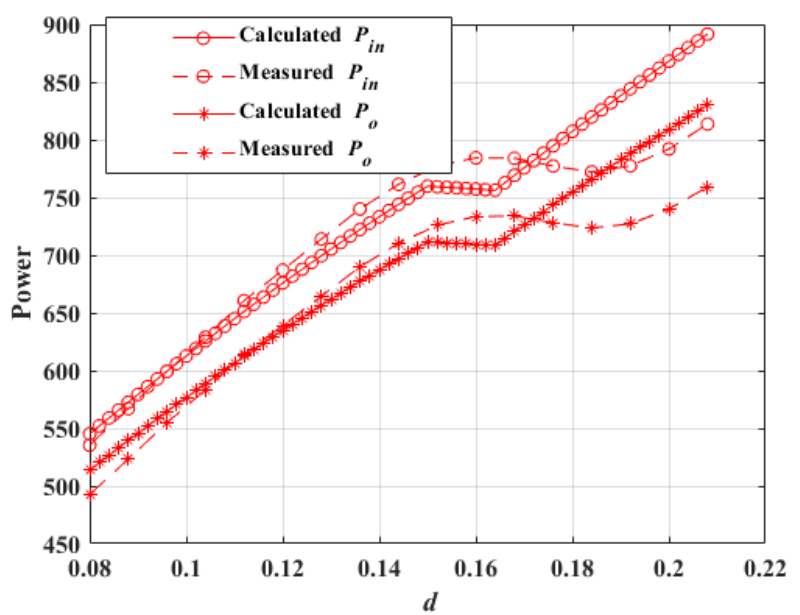

Fig. 22: Measured $P_{\text {in }} \& P_{o}$ vs. $d$ and calculations based on $\mathrm{P}^{2} \mathrm{DAB}$-model-2 @ $V_{1}=300 \mathrm{~V}, V_{2}=25 \mathrm{~V}, T_{d}=70 \mathrm{~ns}$

the power plateau than that outside of the power plateau. Therefore, the hypothesis about efficient power plateau in section III is verified.

Fig. 21 plots the measured anti-power phenomenon at $T_{d L V}=160 \mathrm{~ns}$ at $V_{1} \rightarrow V_{2}$. As shown in the measurements, $P_{i n}$ decreases when $V_{2}$ increases at specific ranges of $V_{2}$. Therefore, the anti-power phenomenon does exist. The measurements of $P_{o}$ is not given since it has the same characteristics as $P_{i n}$.

\section{B. Verification of the $P^{2} D A B-M o d e l-2$}

As mentioned, compared to $\mathrm{P}^{2} \mathrm{DAB}-\mathrm{Model}-1, \mathrm{P}^{2} \mathrm{DAB}-$ Model-2, which is generated from the improved universal power flow model, is expected to be more accurate at predicting the location and the length of the power plateau. Therefore, Fig. 10, which is the plot of the experimental verification of $\mathrm{P}^{2}$ DAB-Model-1, is used as the reference for the following verification of $\mathrm{P}^{2} \mathrm{DAB}-$ Model-2.

The plot of the experimental verification of $\mathrm{P}^{2} \mathrm{DAB}-$ Model-2 is given in Fig. 22. As shown, the maximum error is decreased from $23 \%$ in Fig. 10 to $10 \%$ in Fig. 22. The measured power plateau shifted to the right side of the calculated one. And there is certain mismatch between measured length of the power plateau and the calculated one. Therefore, the calculated 


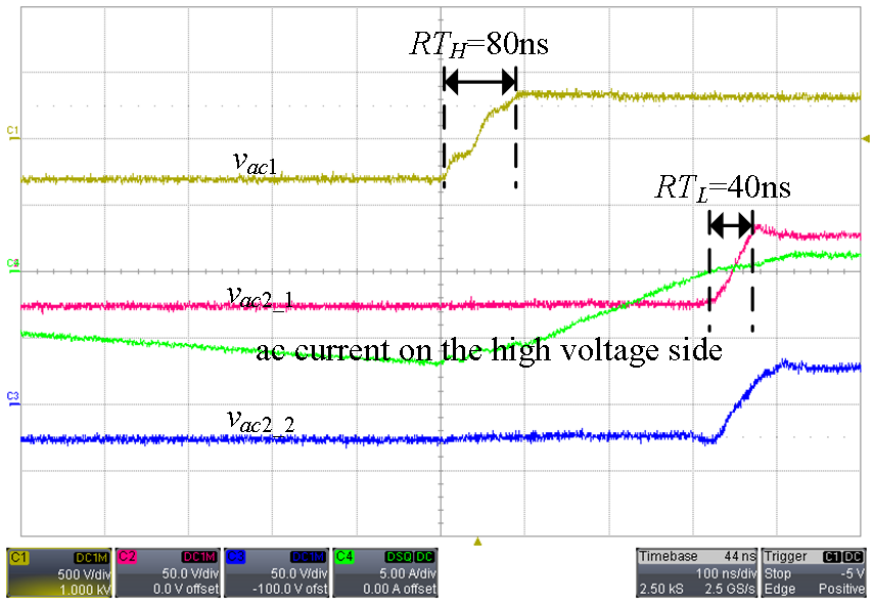

Fig. 23: Measured waveforms @ $V_{1}=300 \mathrm{~V}, V_{2}=25 \mathrm{~V}$, $T_{d H V}=206 \mathrm{~ns}, T_{d L V}=70 \mathrm{~ns}, d=0.2$

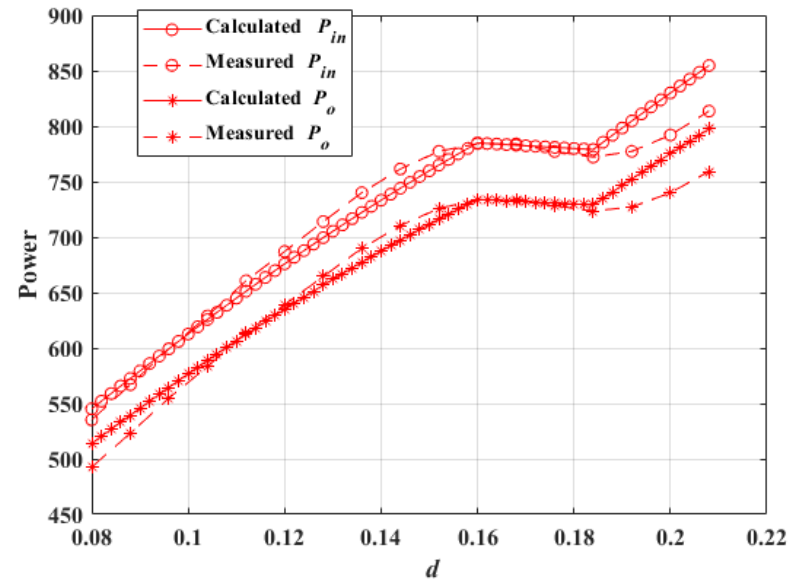

Fig. 24: Measured $P_{\text {in }} \& P_{o}$ vs. $d$ and calculations based on $\mathrm{P}^{2} \mathrm{DAB}-$ model-2 using measured rising time of switching node voltages @ $V_{1}=300 \mathrm{~V}, V_{2}=25 \mathrm{~V}, T_{d}=70 \mathrm{~ns}$

rise time of the switching node voltages has certain error compared to the measurements. The calculated $R T_{H}$ is 23 ns. The calculated $R T_{L}$ is $55 \mathrm{~ns}$. Fig. 23 shows the measured waveforms of the prototype during experimental verification of $\mathrm{P}^{2} \mathrm{DAB}-M o d e l-2$. As shown, the measured $R T_{H}$ is $80 \mathrm{~ns}$; the measured $R T_{L}$ is $40 \mathrm{~ns}$. Fig. 24 gives the calculated power flow based on $\mathrm{P}^{2} \mathrm{DAB}-$ Model-2 using the measured $R T_{H} \&$ $R T_{L}$. As shown, with calibrated $R T_{H} \& R T_{L}$, the maximum error is decreased to $5 \%$. The calculated length and location of the power plateau match with the measured ones. Therefore, the analysis on the influences of resonant commutations on the length and the location of the power plateau is verified. The cause of the $5 \%$ error at large $d$ is unclear. One observation of the mismatch is that, the predicted power increases faster than the measured power after the ending of the power plateau. If the gradually increased rate of change of the power can be modeled, the model will have improved accuracy. However, the reasons for the gradually increased rate of change of the power are unclear. Investigating the possible reasons could be part of the future work.

Since $R T_{H} \& R T_{L}$ is not accurately modeled, $\mathrm{P}^{2} \mathrm{DAB}-$ Model-2 still has a maximum error of $10 \%$. Improving the modeling of $R T_{H} \& R T_{L}$ could also be part of the future work.

\section{CONCLUSION}

In this paper, an improved universal power flow model for DAB-based converters with PSM is derived. The improved model considers the resonant commutations of the bridges in the converters. $\mathrm{P}^{2} \mathrm{DAB}-$ Model-2 is generated from the improved model to investigate the power flow characteristics of the $\mathrm{P}^{2} \mathrm{DAB}$ converter. The power plateau phenomenon, where the input/output power is unable to be regulated, and the anti-power phenomenon, where the input/output power decreases with an increasing output voltage, of the $\mathrm{P}^{2} \mathrm{DAB}$ converter are studied based on $\mathrm{P}^{2} \mathrm{DAB}-$ Model-2. The cause of these phenomenon is determined to be that the inductor current become in-phase with the voltage across the switching nodes of the lagging bridges. The dead time and the resonant commutations are determined to be the parameter which affects the characteristics of these phenomenon most. The power plateau increases the minimum power flow of the $\mathrm{P}^{2} \mathrm{DAB}$ converter, and it does not change the maximum power flow. During the power plateau, there is no reactive power loss in the lagging full-bridge, all the switches achieve zero-voltage-turn-on, and all the switches in the lagging fullbridge achieve zero-current-commutation. A hypothesis, which claims that the $\mathrm{P}^{2} \mathrm{DAB}$ converter should be more efficient on the power plateau than other operation modes, is thereby made. The analysis on the power plateau phenomenon and the anti-power phenomenon and the hypothesis are verified by experiments on a $\mathrm{GaN} \mathrm{P}^{2} \mathrm{DAB}$ prototype. Compared to measurements, $\mathrm{P}^{2} \mathrm{DAB}-$ Model-2 has a maximum error of $10 \%$. The error is due to the inaccurate calculations of the rising time of the switching node voltages. Substituting the measured rising time of the switching node voltages into $\mathrm{P}^{2} \mathrm{DAB}-$ Model-2, the maximum error is decreased to $5 \%$. The derived models are complicated in formulation. Therefore, the model written in MATLAB script and a simulation app 'PowerDAB', which packages the model, are published under an open source license. The models can be easily used for static optimization of DAB based converters. However, due to the models' complexity, it is hard to directly write them into digital controllers to implement model-based predictive control.

\section{REFERENCES}

[1] Y. Xu and C. W. Singh, "Power system reliability impact of energy storage integration with intelligent operation strategy", IEEE Trans. Smart Grid, vol 5, no. 2, pp. 1129-1137, Aug. 2013.

[2] B. Li, F.C. Lee, Q. Li and Z.Y. Liu, "Bi-directional on-board charger architecture and control for achieving ultra-high efficiency with wide battery voltage range", IEEE Applied Power Electronics Conference and Exposition (APEC), pp. 3688-3694, Mar. 2017.

[3] R.M. Burkart, and J.W. Kolar, "Comparative ita-ro-theta pareto optimization of $\mathrm{Si}$ and $\mathrm{SiC}$ multilevel Dual-Active-Bridge topologies with wide input voltage range", IEEE Trans. Power Electronics, vol. 32, no. 7, pp. 5258-5270, Jul. 2017. 
[4] F. Xue, R.Y. Yu, and A.Q. Huang, "A 98.3\% efficient GaN isolated bidirectional DC-DC converter for DC Microgrid energy storage system applications", IEEE Trans. Industrial Electronics, vol. 64, no. 11, pp. 9094-9103, Mar. 2017

[5] A.J.B. Bottion, and I. Barbi, "Input-series and output-series connected modular output capacitor full-bridge PWM DC-DC converter", IEEE Trans. Industrial Electronics, vol. 62, no. 10, pp. 6213-6221, Oct. 2015.

[6] R. Ramachandran, and M. Nymand, "Experimental demonstration of a 98.8\% efficient isolated DC-DC GaN Converter", IEEE Trans. Industrial Electronics, vol. 64, no. 11, pp. 9104-9113, Nov. 2017.

[7] H. F. Fan, and H. Li, "High-frequency transformer isolated bidirectional DC-DC converter modules with high efficiency over wide load range for 20kVA solid-state transformer", IEEE Trans. Power Electronics, vol. 26, no. 12, pp. 3599-3608, Dec. 2011

[8] B. Zhao, Q. Song, J.G. Li, X.P. Xu, and W.H. Liu, "Comparative analysis of multilevel-high-frequency-link and multilevel-dc-link DCDC transformers based on MMC and Dual-Active bridge for MVDC application”, IEEE Trans. Power Electronics, vol. 33, no. 3, pp. 20352049, Mar. 2018

[9] B. Zhao, Q. Song, J.G. Li, Q.H. Sun, and W.H. Liu, "Full-process operation, control, and experiments of modular high-frequency-link DC transformer based on dual active bridge for flexible MVDC distribution", IEEE Trans. Power Electronics, vol. 32, no. 9, pp. 6751-6766, Sept. 2017.

[10] H.S. Qin, and J.W. Kimball, "Solid-State transformer architecture using AC-AC dual-active-bridge converter", IEEE Trans. Industrial Electronics, vol. 60, no. 9, pp.3720-3730, Sept. 2013.

[11] G. Ortiz, M.G. Leibl, J.E. Huber, and J.W. Kolar, "Design and experimental testing of a resonant DC-DC converter for Solid-State transformers", IEEE Trans. Power Electronics, vol. 32, no. 10, pp. 7534-7542, Oct. 2017.

[12] H, Krishnaswami, and N. Mohan, "Three-port series-resonant DC-DC converter to interface renewable energy sources with bidirectional load and energy storage ports,", IEEE Trans. Power Electronics, vol. 24, no. 10, pp. 2289-2297, Oct. 2009.

[13] K. Tomas-Manez, Z. Zhang, and Z.W. Ouyang, "Multi-port isolated LLC resonant converter for distributed energy generation with energy storage", IEEE Energy Conversion Congress and Exposition (ECCE), pp: 22192226, Oct. 2017.

[14] R.W.A.A.De Doncker, D.M. Divan, M.H. Kheraluwala, "A three-phase soft-switched high-power-density dc/dc converter for high-power applications", IEEE Trans. Industrial Applications, vol. 27, no. 1, pp. 63-73, Jan/Feb. 1991.

[15] B. Zhao, Q. Song, W.H. Liu, Y.D. Sun, "Overview of dual-active bridge isolated bidirectional DC-DC converter for high-frequency link powerconversion system", IEEE Trans. Power Electronics, vol. 29, no. 8, pp. 4091-4106, Aug. 2014.

[16] H. Bai, C.C. Mi, S. Gargies, "The short-time-scale transient processes in high-voltage and high-power isolated bidirectional DC-DC converters", IEEE Transactions on Power Electronics, vol. 23, no. 6, pp. 2648-2656, Nov. 2008

[17] Y.H. Xie, J. Sun, J.S. Freudenberg, "Power flow characterization of a bidirectional galvanically isolated high-power DC/DC converter over a wide operating range", IEEE Transactions on Power Electronics, vol. 25, no. 1, pp. 54-66, Jan. 2010.

[18] F. Krismer, "Modeling and optimization of bidirectional dual active bridge DC-DC converter", Dissertation submitted to ETH Zurich for the Degree of Doctor of Sciences, 2010.

[19] B. Zhao, Q. Song, W.H. Liu, and Y.D. Sun, "Dead time effect of the high frequency isolated bidirectional full bridge dc-dc converter: comprehensive theoretical analysis and experimental verification,", IEEE Trans. Power Electronics, vol. 29, no. 4, pp. 1667-1680, Apr. 2014.

[20] Y. Xiao, Z. Zhang, X.K. Mao, K.T. Manez, M.A.E. Andersen, ”Power plateau and anti-power phenomenon of dual active bridge converter with phase-shift modulation", 2018 IEEE Applied Power Electronics Conference and Exposition (APEC), 2018.

[21] Z. Zhang, K. Tomas-Manez, Y.D. Xiao, M.A.E. Andersen, "High voltage gain dual active bridge converter with an extended operation range for renewable energy systems", 2018 IEEE Applied Power Electronics Conference and Exposition (APEC), 2018

[22] Y.D. Xiao, Z. Zhang, M.A.E. Andersen, B.E.Thomsen "Partial Parallel Dual Active Bridge Converter with Variable Voltage Gain for SOEC/SOFC System", 2019 IEEE Applied Power Electronics Conference and Exposition (APEC), 2019.

[23] Y. Xiao, Z. Zhang, M.A.E. Andersen, "Power flow models of GaN Based Partial Parallel Dual Active Bridge ( $\left.{ }^{2} \mathrm{DAB}\right)$ DC-DC Converter", 2nd IEEE International Power Electronics and Application Conference and Exposition (PEAC), 2018.
[24] P. Zumel, L. Ortega, A. Lázaro, C. Fernández, A. Barrado, A. Rodríguez, and M. M. Hernando, "Modular Dual-Active Bridge Converter Architecture", IEEE Transactions on Industry Applications, vol. 52, no. 3, pp. 2444-2455, May. 2016.

[25] "PowerDAB", Link to GitHub repository: https://github.com/YudiXiao/PowerDAB, Technical University of Denmark, Department of Electrical Engineering, 2020(initial version).

[26] N. Hou, W. Song and M. Wu, "Minimum-Current-Stress Scheme of Dual Active Bridge DC-DC Converter With Unified Phase-Shift Control", IEEE Trans. Power Electronics, vol. 31, no. 12, pp. 8552-8561, Dec. 2016.

[27] W. Song, N. Hou and M. Wu, "Virtual Direct Power Control Scheme of Dual Active Bridge DC-DC Converters for Fast Dynamic Response", IEEE Trans. Power Electronics, vol. 33, no. 2, pp. 1750-1759, Feb. 2018

[28] N. Hou, W. Song, Y. Li, Y. Zhu and Y. Zhu, "A Comprehensive Optimization Control of Dual-Active-Bridge DC-DC Converters Based on Unified-Phase-Shift and Power-Balancing Scheme", IEEE Trans. on Power Electronics, vol. 34, no. 1, pp. 826-839, Jan. 2019.

[29] N. Hou and Y. W. Li, "Overview and Comparison of Modulation and Control Strategies for a Nonresonant Single-Phase Dual-Active-Bridge DC-DC Converter", IEEE Trans. on Power Electronics, vol. 35, no. 3, pp. 3148-3172, March 2020. 


\section{APPENDIX}

The following are the power flow equations of the improved universal power flow model for DAB-Based converter with SPSM. Since the equations of current integrations are of the same form for all of the operation conditions, they are only given once as in (29).

(29) $V_{1} \rightarrow V_{2}$, Mode $a$ :

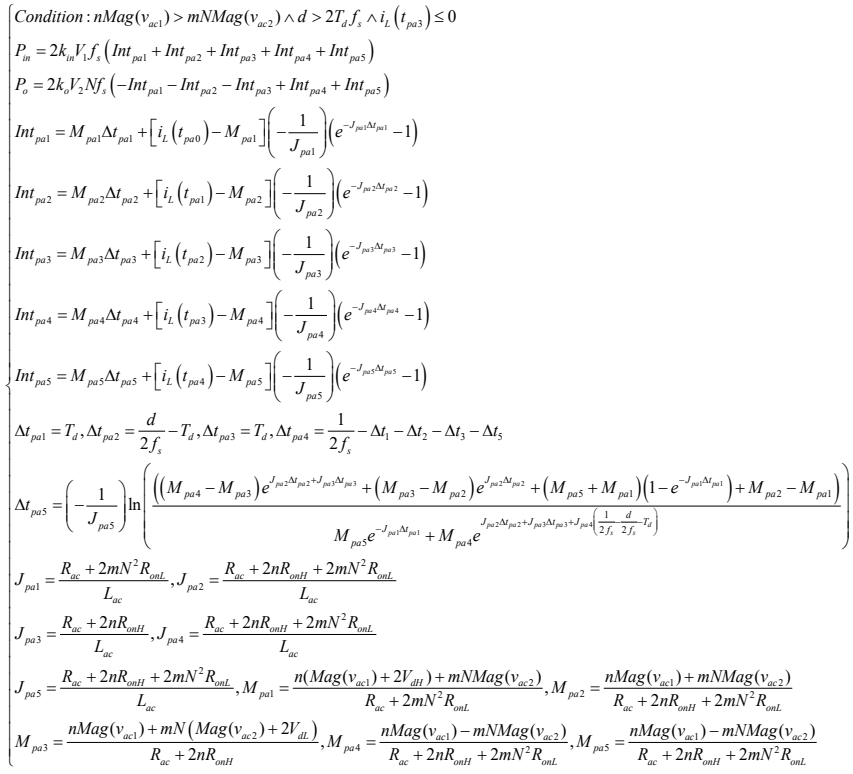

(30) $V_{1} \rightarrow V_{2}$, Mode $b$ :

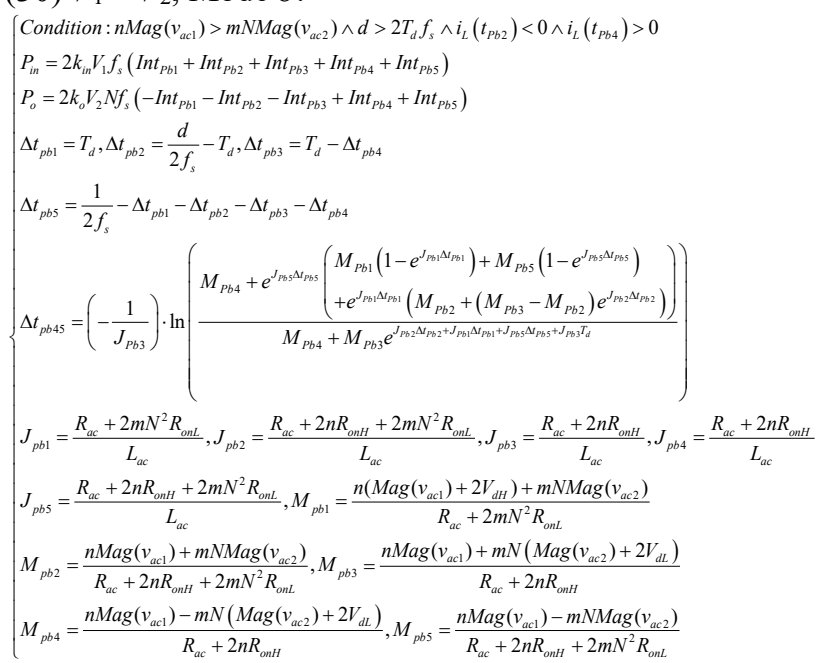

(31) $V_{1} \rightarrow V_{2}$, Mode $c$ :
Condition: $n \operatorname{Mag}\left(v_{a c 1}\right)>m N M a g\left(v_{a c 2}\right) \wedge d>2 T_{d} f_{s} \wedge i_{L}\left(t_{P c 3}\right) \geq 0$

$P_{i n}=2 k_{i n} V_{1} f_{s}\left(I n t_{P_{c 1}}+\operatorname{Int}_{P_{c 2}}+\operatorname{Int}_{P_{C c} 3}+\operatorname{Int}_{P_{c 4}}+\operatorname{Int} t_{P c 5}\right)$

$P_{o}=2 k_{o} V_{2} N f_{s}\left(-\operatorname{Int} t_{P c 1}-I n t_{P c 2}-\operatorname{Int}_{P c 3}+\operatorname{Int}_{P c 4}+\operatorname{Int} t_{P c 5}\right)$

$\Delta t_{1 p c}=T_{d}, \Delta t_{p c 2}=\frac{d}{2 f_{s}}-T_{d}-\Delta t_{p c 3}, \Delta t_{p c 5}=\frac{1}{2 f_{s}}-\frac{d}{2 f_{s}}-T_{d}, \Delta t_{p c 4}=T_{d}$

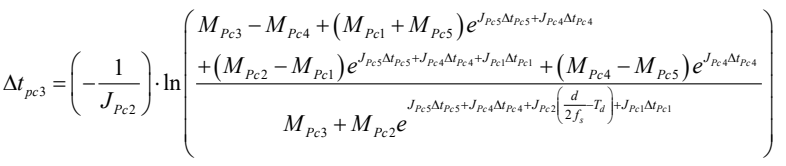

$J_{p c 1}=\frac{R_{a c}+2 m N^{2} R_{o n L}}{L_{a c}}, J_{p c 2}=\frac{R_{a c}+2 n R_{o n H}+2 m N^{2} R_{o n L}}{L_{a c}}$

$J_{p c 3}=\frac{R_{a c}+2 n R_{o n H}+2 m N^{2} R_{o n L}}{L_{a c}}, J_{p c 4}=\frac{R_{a c}+2 n R_{o n H}}{L_{a c}}$

$J_{p c 5}=\frac{R_{a c}+2 n R_{o n H}+2 m N^{2} R_{o n L}}{L_{a c}}, M_{p c 1}=\frac{n\left(\operatorname{Mag}\left(v_{a c 1}\right)+2 V_{d H}\right)+m N M a g\left(v_{a c 2}\right)}{R_{a c}+2 m N^{2} R_{o n L}}$

$M_{p c 2}=\frac{n \operatorname{Mag}\left(v_{a c 1}\right)+m \operatorname{NMag}\left(v_{a c 2}\right)}{R_{a c}+2 n R_{o n H}+2 m N^{2} R_{o n L}}, M_{p c 3}=\frac{n \operatorname{Mag}\left(v_{a c 1}\right)+m \operatorname{NMag}\left(v_{a c 2}\right)}{R_{a c}+2 n R_{o n H}+2 m N^{2} R_{o n L}}$

$M_{p c 4}=\frac{n M a g\left(v_{a c 1}\right)-m N\left(\operatorname{Mag}\left(v_{a c 2}\right)+2 V_{d L}\right)}{R_{a c}+2 n R_{o n H}}, M_{p c 5}=\frac{n \operatorname{Mag}\left(v_{a c 1}\right)-m N M a g\left(v_{a c 2}\right)}{R_{a c}+2 n R_{o n H}+2 m N^{2} R_{o n L}}$

(32) $V_{1} \rightarrow V_{2}$, Mode $d$ :

Condition: $n \operatorname{Mag}\left(v_{a c 1}\right)<m N M a g\left(v_{a c 2}\right) \wedge d>2 T_{d} f_{s} \wedge i_{L}\left(t_{P d 0}\right) \geq 0$

$P_{i n}=2 k_{i n} V_{1} f_{s}\left(-I n t_{P d 1}+I n t_{P d 2}+I n t_{P d 3}+I n t_{P d 4}+I n t_{P d 5}\right)$

$P_{o}=2 k_{o} V_{2} N f_{s}\left(-I n t_{P d 1}-I n t_{P d 2}+\operatorname{Int} t_{P d 3}+I n t_{P d 4}+\operatorname{Int} t_{P d 5}\right)$

$\Delta t_{p d 1}=T_{d}, \Delta t_{p d 2}=\frac{d}{2 f_{s}}-T_{d}, \Delta t_{p d 3}=T_{d}, \Delta t_{p d 5}=\frac{1}{2 f_{s}}-\frac{d}{2 f_{s}}-T_{d}-\Delta t_{P d 4}$

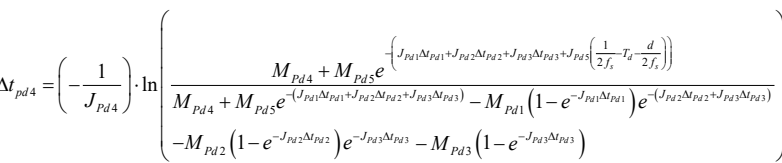

$J_{p d 1}=\frac{R_{a c}+2 m N^{2} R_{o n L}}{L_{a c}}, J_{p d 2}=\frac{R_{a c}+2 n R_{o n H}+2 m N^{2} R_{o n L}}{L_{a c}}, J_{p d 3}=\frac{R_{a c}+2 n R_{o n H}}{L_{a c}}$

$J_{p d 4}=\frac{R_{a c}+2 n R_{o n H}+2 m N^{2} R_{o n L}}{L}, J_{p d s}=\frac{R_{a c}+2 n R_{o n H}+2 m N^{2} R_{o n L}}{L}$

$M_{p d 1}=\frac{-n\left(\operatorname{Mag}\left(v_{a c 1}\right)+2 V_{d H}\right)+m N \operatorname{Mag}\left(v_{a c 2}\right)}{R_{a c}+2 m N^{2} R_{o n L}}, M_{p d 2}=\frac{n \operatorname{Mag}\left(v_{a c 1}\right)+m N M a g\left(v_{a c 2}\right)}{R_{a c}+2 n R_{o n H}+2 m N^{2} R_{o n L}}$

$M_{p d 3}=\frac{n M a g\left(v_{a c 1}\right)-m N\left(\operatorname{Mag}\left(v_{a c 2}\right)+2 V_{d L}\right)}{R_{a c}+2 n R_{o n H}}, M_{p d 4}=\frac{n \operatorname{Mag}\left(v_{a c 1}\right)-m N M a g\left(v_{a c 2}\right)}{R_{a c}+2 n R_{o n H}+2 m N^{2} R_{o n L}}$

$M_{p d 5}=\frac{n \operatorname{Mag}\left(v_{a c 1}\right)-m N \operatorname{Mag}\left(v_{a c 2}\right)}{R+2 n R+2 m N^{2} R}$

(33) $V_{1} \rightarrow V_{2}$, Mode $e$ :

Condition : $n \operatorname{Mag}\left(v_{a c 1}\right)<m N M a g\left(v_{a c 2}\right) \wedge d>2 T_{d} f_{s} \wedge i_{L}\left(t_{P e 0}\right)<0 \wedge i_{L}\left(t_{P e 2}\right)>0$

$P_{i n}=2 k_{i n} V_{1} f_{s}\left(\operatorname{Int}_{P_{e 1}}-\operatorname{Int}_{P_{e 2}}+\operatorname{Int}_{P_{e 3}}+\operatorname{Int}_{P_{e 4}}+\operatorname{Int}_{P_{e s}}\right)$

$P_{o}=2 k_{o} V_{2} N f_{s}\left(-\operatorname{Int}_{P_{e 1}}-\operatorname{Int}_{P_{e 2}}-\operatorname{Int}_{P e 3}+\operatorname{Int}_{P_{e} 4}+\operatorname{Int}_{P e s}\right)$

$\Delta t_{p e 2}=T_{d}-\Delta t_{P e 1}, \Delta t_{p e 3}=\frac{d}{2 f_{s}}-T_{d}, \Delta t_{p e 4}=T_{d}, \Delta t_{p e 5}=\frac{1}{2 f_{s}}-\frac{d}{2 f_{s}}-T_{d}$

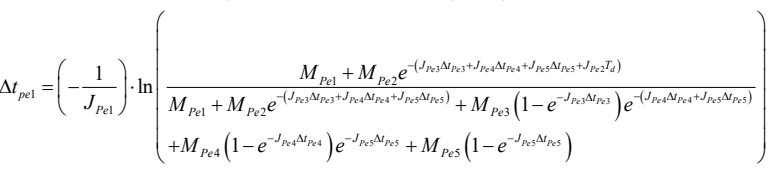

$J_{p e 1}=\frac{R_{a c}+2 m N^{2} R_{o n L}}{L_{a c}}, J_{p e 2}=\frac{R_{a c}+2 m N^{2} R_{o n L}}{L_{a c}}, J_{p e 3}=\frac{R_{a c}+2 n R_{o n H}+2 m N^{2} R_{o n L}}{L_{a c}}$

$J_{p e 4}=\frac{R_{a c}+2 n R_{o n H}}{L_{a c}}, J_{p e 5}=\frac{R_{a c}+2 n R_{o n H}+2 m N^{2} R_{o n L}}{L_{a c}}$

$M_{p e 1}=\frac{n\left(\operatorname{Mag}\left(v_{a c 1}\right)+2 V_{d H}\right)+m N M a g\left(v_{a c 2}\right)}{R_{a c}+2 m N^{2} R_{o n L}}, M_{p e 2}=\frac{-n\left(\operatorname{Mag}\left(v_{a c 1}\right)+2 V_{d H}\right)+m N M a g\left(v_{a c 2}\right)}{R_{a c}+2 m N^{2} R_{o n L}}$

$M_{p e 3}=\frac{n \operatorname{Mag}\left(v_{a c 1}\right)+m N M a g\left(v_{a c 2}\right)}{R_{a c}+2 n R_{o n H}+2 m N^{2} R_{o n L}}, M_{p e 4}=\frac{n M a g\left(v_{a c 1}\right)-m N\left(\operatorname{Mag}\left(v_{a c 2}\right)+2 V_{a L}\right)}{R_{a c}+2 n R_{o n H}}$

$M_{p e s}=\frac{n \operatorname{Mag}\left(v_{a c 1}\right)-m N M a g\left(v_{a c 2}\right)}{R_{a c}+2 n R_{o n H}+2 m N^{2} R_{o n L}}$

(34) $V_{1} \rightarrow V_{2}$, Mode $f$ : 


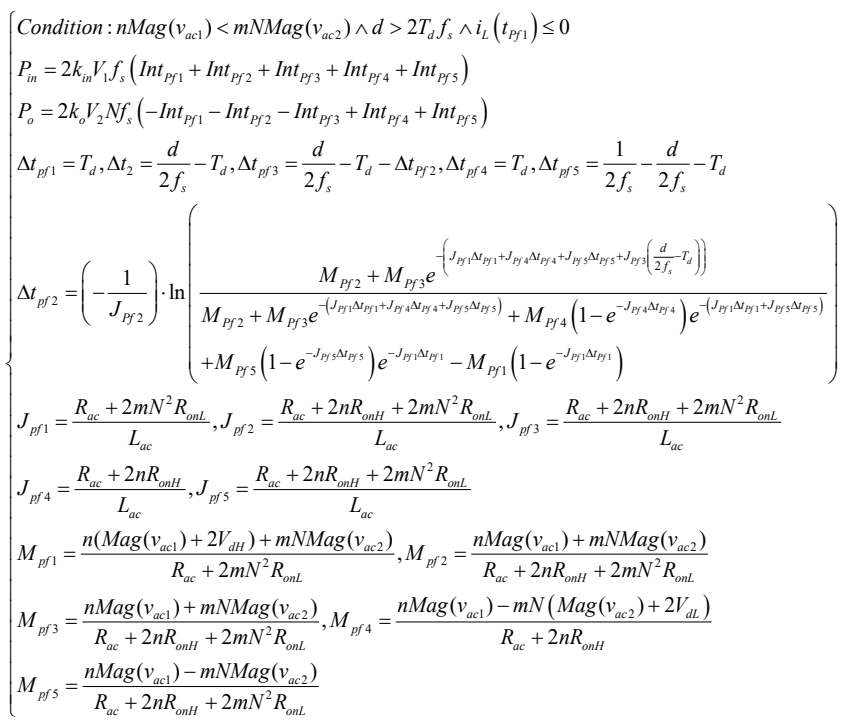

(35) $V_{1} \rightarrow V_{2}$, Mode $g:$

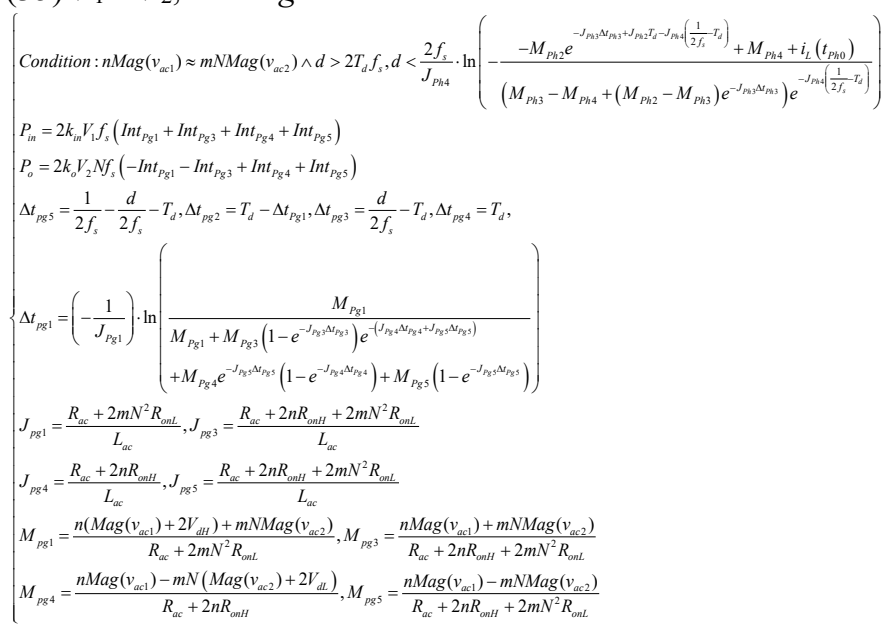

(36) $V_{1} \rightarrow V_{2}$, Mode $h$ :

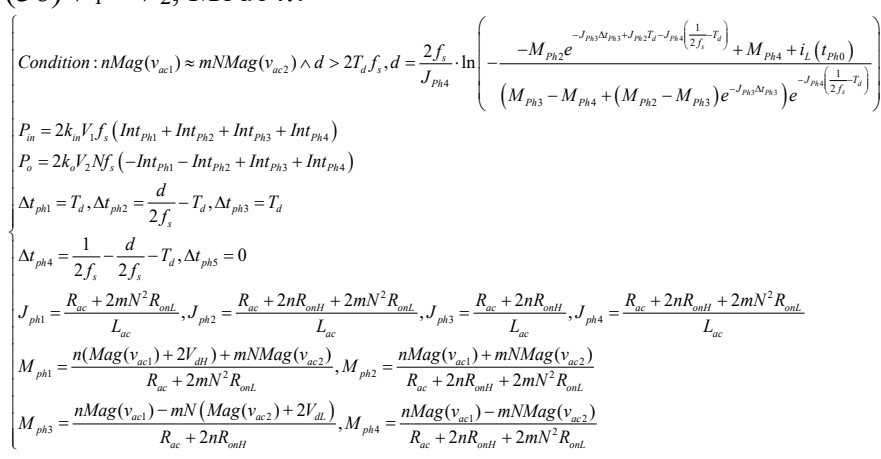

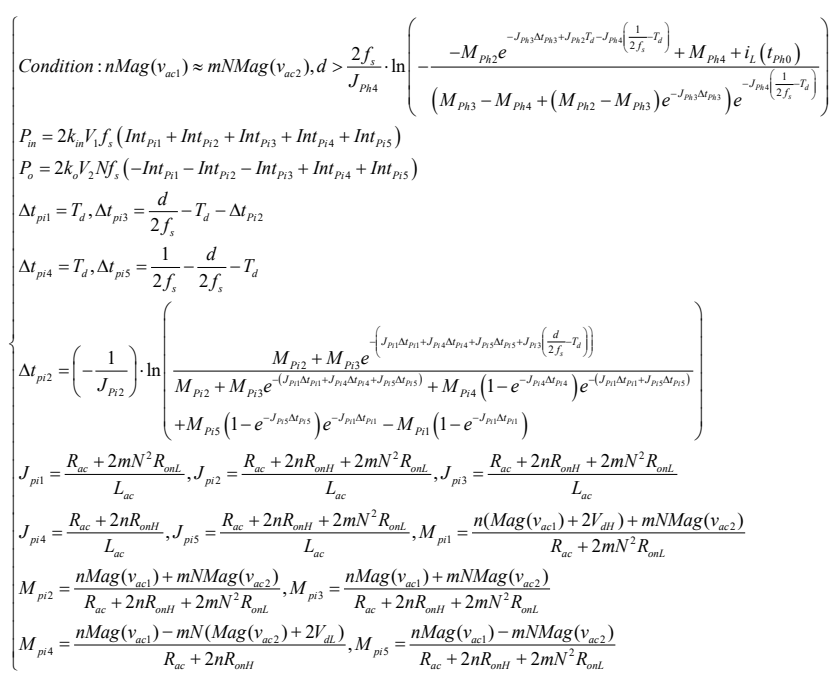

(38) $V_{2} \rightarrow V_{1}$, Mode $a$ :

Condition: $\operatorname{mNMag}\left(v_{a c 2}\right)>n M a g\left(v_{a c 1}\right) \wedge-d>2 T_{d} f_{s} \wedge i_{L}\left(t_{N a 3}\right) \leq 0$

$P_{i n}=-2 k_{i n} V_{1} f_{s}\left(-I n t_{P a 1}-I n t_{P a 2}-\operatorname{Int}_{P a 3}+I n t_{P a 4}+\operatorname{Int} t_{P a s}\right)$

$P_{o}=-2 k_{o} V_{2} N f_{s}\left(\operatorname{Int}_{P a 1}+\operatorname{Int}_{P a 2}+\operatorname{Int}_{P a 3}+\operatorname{Int}_{P a 4}+\operatorname{Int}_{P_{a 4}}\right)$

$\Delta t_{n a 1}=T_{d}, \Delta t_{n a 2}=\frac{-d}{2 f_{s}}-T_{d}, \Delta t_{n a 3}=T_{d}, \Delta t_{n a 4}=\frac{1}{2 f_{s}}-\frac{-d}{2 f_{s}}-T_{d}-\Delta t_{N a}$

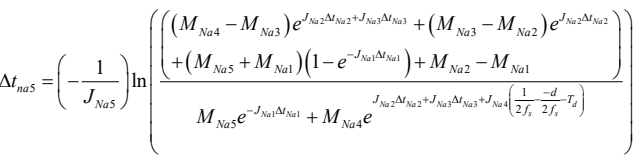

$J_{n a 1}=\frac{R_{a c}+2 n R_{o n H}}{L_{a c}}, J_{n a 2}=\frac{R_{a c}+2 n R_{o n H}+2 m N^{2} R_{o n L}}{L_{a c}}$

$J_{n a 3}=\frac{R_{a c}+2 m N^{2} R_{o n L}}{L_{a c}}, J_{n a 4}=\frac{R_{a c}+2 n R_{o n H}+2 m N^{2} R_{o n L}}{L_{a c}}$

$J_{n a 5}=\frac{R_{a c}+2 n R_{o n H}+2 m N^{2} R_{o n L}}{L_{a c}}, M_{n a 1}=\frac{n M a g\left(v_{a c 1}\right)+m N\left(M a g\left(v_{a c 2}\right)+2 V_{d L}\right)}{R_{c c}+2 n R_{o u}}$

$M_{n a 2}=\frac{n M a g\left(v_{a c 1}\right)+m N M a g\left(v_{a c 2}\right)}{R+2 n R}, M_{n a 3}=\frac{n\left(\operatorname{Mag}\left(v_{a c 1}\right)+V_{d H}\right)+m N M a g\left(v_{a c 2}\right)}{R}$

$M_{n a 4}=\frac{m N \operatorname{Mag}\left(v_{a c 2}\right)-n \operatorname{Mag}\left(v_{a c 1}\right)}{R_{a c}+2 n R_{o n H}+2 m N^{2} R_{o n L}}, M_{n a 5}=\frac{m N M a g\left(v_{a c 2}\right)-n \operatorname{Mag}\left(v_{a c 1}\right)}{R_{a c}+2 n R_{o n H}+2 m N^{2} R_{o n L}}$

(39) $V_{2} \rightarrow V_{1}$, Mode $b$ :

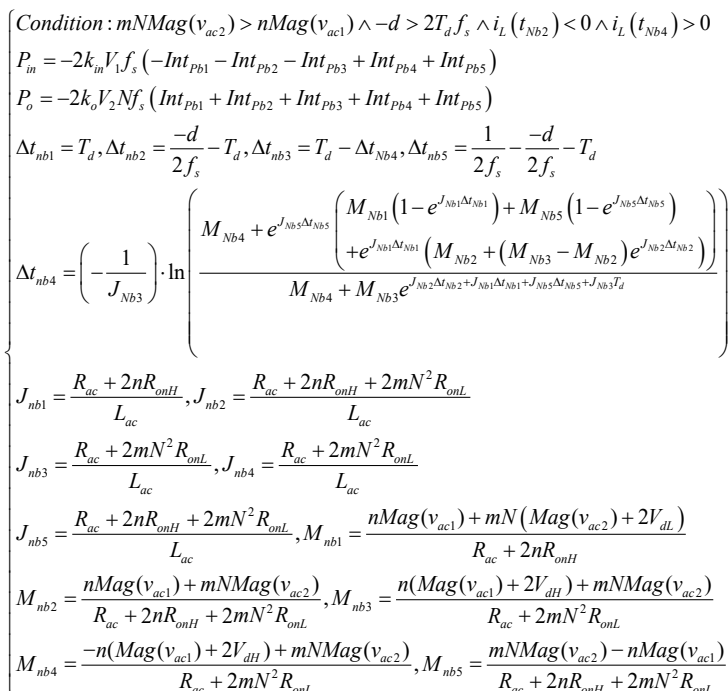

(40) $V_{2} \rightarrow V_{1}$, Mode $c$ : 
Condition: $m \operatorname{NMag}\left(v_{a c 2}\right)>n \operatorname{Mag}\left(v_{a c 1}\right) \wedge-d>2 T_{d} f_{s} \wedge i_{L}\left(t_{N c 3}\right) \geq 0$

$P_{i n}=-2 k_{i n} V_{1} f_{s}\left(-I n t_{P c 1}-\operatorname{Int}_{P_{C 2} 2}-\operatorname{Int}_{P_{C 3} 3}+\operatorname{Int}_{P_{c 4}}+\operatorname{Int}_{P_{c 5}}\right)$

$P_{o}=-2 k_{o} V_{2} N f_{s}\left(\operatorname{Int}_{P C 1}+\operatorname{Int} t_{P c 2}+\operatorname{Int} t_{P c 3}+\operatorname{Int} t_{P C 4}+\operatorname{Int} t_{P c 5}\right)$

$\Delta t_{n c 1}=T_{d}, \Delta t_{n c 2}=\frac{-d}{2 f_{s}}-T_{d}-\Delta t_{N c 3}, \Delta t_{n c 4}=T_{d}, \Delta t_{n c 5}=\frac{1}{2 f_{s}}-\frac{-d}{2 f_{s}}-T_{d}$

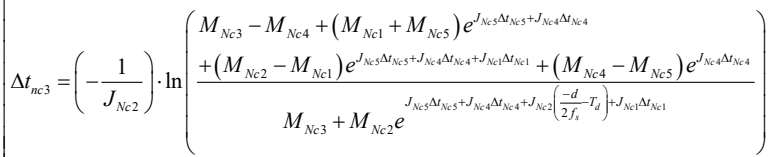

$J_{n c 1}=\frac{R_{a c}+2 n R_{o n H}}{L_{a c}}, J_{n c 2}=\frac{R_{a c}+2 n R_{o n H}+2 m N^{2} R_{o n L}}{L_{a c}}, J_{n c 3}=\frac{R_{a c}+2 n R_{o n H}+2 m N^{2} R_{o n L}}{L_{a c}}$

$J_{n c 4}=\frac{R_{a c}+2 m N^{2} R_{o n L}}{L}, J_{n c 5}=\frac{R_{a c}+2 n R_{o n H}+2 m N^{2} R_{o n L}}{L}$

$M_{n c 1}=\frac{n \operatorname{Mag}\left(v_{a c 1}\right)+m N\left(\operatorname{Mag}\left(v_{a c 2}\right)+2 V_{d L}\right)}{R+2 n R}, M_{n c 2}=\frac{n \operatorname{Mag}\left(v_{a c 1}\right)+m N \operatorname{Mag}\left(v_{a c 2}\right)}{R+2 n R+2 m N^{2} R}$

$M_{n c 3}=\frac{n \operatorname{Mag}\left(v_{a c 1}\right)+m N \operatorname{Mag}\left(v_{a c 2}\right)}{R+2 n R+2 m N^{2} R}, M_{n c 4}=\frac{m N M a g\left(v_{a c 2}\right)-n\left(\operatorname{Mag}\left(v_{a c 1}\right)+2 V_{d H}\right)}{R+2 m N^{2} R}$

$M_{n c 5}=\frac{m N M a g\left(v_{a c 2}\right)-n \operatorname{Mag}\left(v_{a c 1}\right)}{R+2 n R+2 m N^{2} R}$

(41) $V_{2} \rightarrow V_{1}$, Mode $d:$

Condition: $\operatorname{mNMag}\left(v_{a c 2}\right)<n \operatorname{Mag}\left(v_{a c 1}\right) \wedge-d>2 T_{d} f_{s} \wedge i_{L}\left(t_{\text {Nd0 }}\right) \geq 0$

$P_{i n}=-2 k_{i n} V_{1} f_{s}\left(-I n t_{P d 1}-\operatorname{Int}_{P d 2}+\operatorname{Int}_{P d 3}+\operatorname{Int}_{P d 4}+\operatorname{Int}_{P d 5}\right)$

$P_{o}=-2 k_{o} V_{2} N f_{s}\left(-I n t_{P d 1}+I n t_{P d 2}+I n t_{P d 3}+I n t_{P d 4}+\operatorname{Int} t_{P d}\right)$

$\Delta t_{n d 1}=T_{d}, \Delta t_{n d 2}=\frac{-d}{2 f_{s}}-T_{d}, \Delta t_{n d 3}=T_{d}, \Delta t_{n d 5}=\frac{1}{2 f_{s}}-\frac{-d}{2 f_{s}}-T_{d}-\Delta t_{N d 4}$

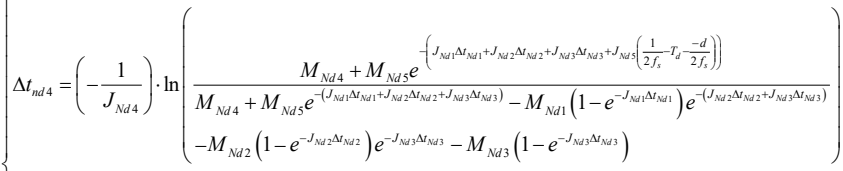

$J_{n d 1}=\frac{R_{a c}+2 n R_{o n H}}{L_{a c}}, J_{n d 2}=\frac{R_{a c}+2 n R_{o n H}+2 m N^{2} R_{o n L}}{L_{a c}}, J_{n d 3}=\frac{R_{a c}+2 m N^{2} R_{o n L}}{L_{a c}}$

$J_{n d 4}=\frac{R_{a c}+2 n R_{o n H}+2 m N^{2} R_{o n L}}{L_{a c}}, J_{n d 5}=\frac{R_{a c}+2 n R_{o n H}+2 m N^{2} R_{o n L}}{L_{a c}}$

$M_{n d 1}=\frac{n M a g\left(v_{a c 1}\right)-m N\left(\operatorname{Mag}\left(v_{a c 2}\right)+2 V_{d L}\right)}{R_{a c}+2 n R_{o n H}}, M_{n d 2}=\frac{n \operatorname{Mag}\left(v_{a c 1}\right)+m N M a g\left(v_{a c 2}\right)}{R_{a c}+2 n R_{o n H}+2 m N^{2} R_{o n L}}$

$M_{n d 3}=\frac{m N M a g\left(v_{a c 2}\right)-n\left(\operatorname{Mag}\left(v_{a c 1}\right)+2 V_{d H}\right)}{R_{a c}+2 m N^{2} R_{o n L}}, M_{n d 4}=\frac{m N M a g\left(v_{a c 2}\right)-n M a g\left(v_{a c 1}\right)}{R_{a c}+2 n R_{o n H}+2 m N^{2} R_{o n L}}$

$M_{n d 5}=\frac{m N M a g\left(v_{a c 2}\right)-n M a g\left(v_{a c 1}\right)}{R_{a c}+2 n R_{o n H}+2 m N^{2} R_{o n L}}$

(42) $V_{2} \rightarrow V_{1}$, Mode $e$ :

Condition : $m N M a g\left(v_{a c 2}\right)<n M a g\left(v_{a c 1}\right) \wedge-d>2 T_{d} f_{s} \wedge i_{L}\left(t_{N e 0}\right)<0 \wedge i_{L}\left(t_{N e 2}\right)>0$

$P_{i n}=-2 k_{i n} V_{1} f_{s}\left(-\operatorname{Int}_{P e 1}-\operatorname{Int}_{P e 2}-\operatorname{Int}_{P e 3}+\operatorname{Int}_{P e 4}+\operatorname{Int}_{P e 5}\right)$

$P_{o}=-2 k_{o} V_{2} N f_{s}\left(\operatorname{Int}_{P e 1}-\operatorname{Int}_{P e 2}+\operatorname{Int}_{P e 3}+\operatorname{Int}_{P e 4}+\operatorname{Int}_{P e 5}\right)$

$\Delta t_{n e 2}=T_{d}-\Delta t_{\text {Ne1 }}, \Delta t_{n e 3}=\frac{-d}{2 f_{s}}-T_{d}, \Delta t_{n e 4}=T_{d}, \Delta t_{n e s}=\frac{1}{2 f_{s}}-\frac{-d}{2 f_{s}}-T_{d}$

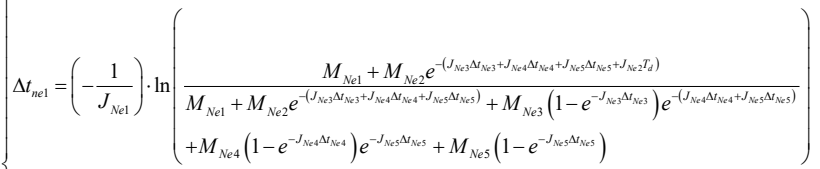

$J_{n e 1}=\frac{R_{a c}+2 n R_{o n H}}{L}, J_{n e 2}=\frac{R_{a c}+2 n R_{o n H}}{L}, J_{n e 3}=\frac{R_{a c}+2 n R_{o n H}+2 m N^{2} R_{o n L}}{L}$

$J_{n e 4}=\frac{R_{a c}+2 m N^{2} R_{o n L}}{L_{a c}}, J_{n e 5}=\frac{R_{a c}+2 n R_{o n H}+2 m N^{2} R_{o n L}}{L_{a c}}$

$M_{n e 1}=\frac{n \operatorname{Mag}\left(v_{a c 1}\right)+m N\left(\operatorname{Mag}\left(v_{a c 2}\right)+2 V_{d L}\right)}{R_{a c}+2 n R_{o n H}}, M_{n e 2}=\frac{-m N\left(\operatorname{Mag}\left(v_{a c 2}\right)+2 V_{d L}\right)+n M a g\left(v_{a c 1}\right)}{R_{a c}+2 n R_{o n H}}$

$M_{n e 3}=\frac{n M a g\left(v_{a c 1}\right)+m N M a g\left(v_{a c 2}\right)}{R_{a c}+2 n R_{o n H}+2 m N^{2} R_{o n L}}, M_{n e 4}=\frac{m N M a g\left(v_{a c 2}\right)-n\left(\operatorname{Mag}\left(v_{a c 1}\right)+2 V_{d H}\right)}{R_{a c}+2 m N^{2} R_{o n L}}$

$M_{n e s}=\frac{m N M a g\left(v_{a c 2}\right)-n M a g\left(v_{a c 1}\right)}{R_{a c}+2 n R_{\text {onH }}+2 m N^{2} R_{\text {onL }}}$

(43) $V_{2} \rightarrow V_{1}$, Mode $f:$
Condition: $\operatorname{mNMag}\left(v_{a c 2}\right)<n M a g\left(v_{a c 1}\right) \wedge-d>2 T_{d} f_{s} \wedge i_{L}\left(t_{N f 1}\right) \leq 0$

$P_{i n}=-2 k_{i n} V_{1} f_{s}\left(-I n t_{P f 1}-I n t_{P f 2}-I n t_{P f 3}+I n t_{P f 4}+I n t_{P f 5}\right)$

$P_{o}=-2 k_{o} V_{2} N f_{s}\left(\operatorname{Int}_{P f 1}+\operatorname{Int}_{P f 2}+\operatorname{Int}_{P f 3}+\operatorname{Int}_{P f 4}+\operatorname{Int}_{P f 5}\right)$

$\Delta t_{n f 1}=T_{d}, \Delta t_{n f 3}=\frac{-d}{2 f_{s}}-T_{d}-\Delta t_{N f 2}, \Delta t_{n f 4}=T_{d}, \Delta t_{n f 5}=\frac{1}{2 f_{s}}-\frac{-d}{2 f_{s}}-T_{d}$

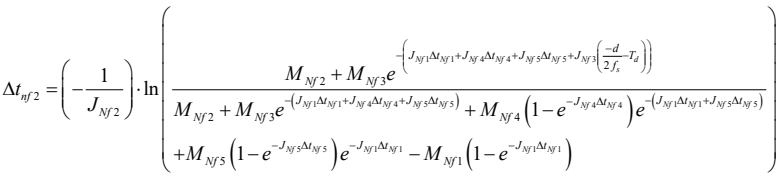

$J_{n f 1}=\frac{R_{a c}+2 n R_{o n H}}{L_{a c}}, J_{n f 2}=\frac{R_{a c}+2 n R_{o n H}+2 m N^{2} R_{o n L}}{L_{a c}}, J_{n f 3}=\frac{R_{a c}+2 n R_{o n H}+2 m N^{2} R_{o n L}}{L_{a c}}$

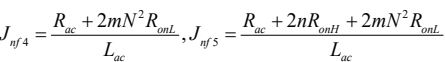

$M_{n f 1}=\frac{n M a g\left(v_{a c 1}\right)+m N\left(\operatorname{Mag}\left(v_{a c 2}\right)+2 V_{d L}\right)}{R+2 n R}, M_{n f 2}=\frac{n \operatorname{Mag}\left(v_{a c 1}\right)+m N M a g\left(v_{a c 2}\right)}{R+2 n R+2 m N^{2} R}$

$M_{n f 3}=\frac{n M a g\left(v_{a c 1}\right)+m N M a g\left(v_{a c 2}\right)}{R_{a c}+2 n R_{o n H}+2 m N^{2} R_{o n L}}, M_{n f 4}=\frac{m N M a g\left(v_{a c 2}\right)-n\left(\operatorname{Mag}\left(v_{a c 1}\right)+2 V_{d H}\right)}{R_{a c}+2 m N^{2} R_{o n L}}$

$M_{n f 5}=\frac{m N M a g\left(v_{a c 2}\right)-n M a g\left(v_{a c 1}\right)}{R_{a c}+2 n R_{o n H}+2 m N^{2} R_{o n L}}$

(44) $V_{2} \rightarrow V_{1}$, Mode $g$ :

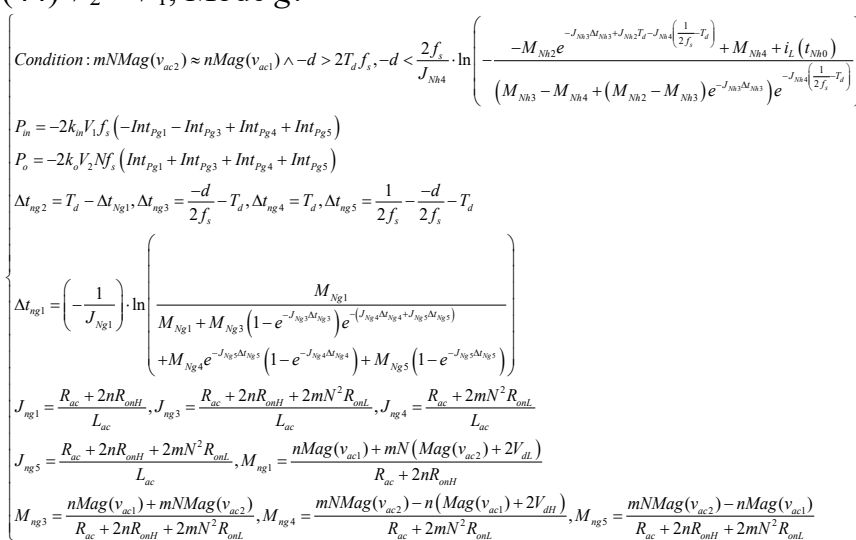

(45) $V_{2} \rightarrow V_{1}$, Mode $h$ :

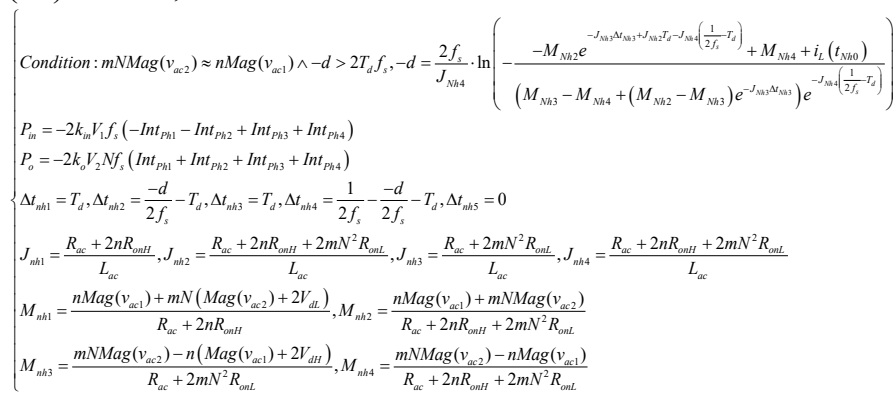

(46) $V_{2} \rightarrow V_{1}$, Mode $i$ :

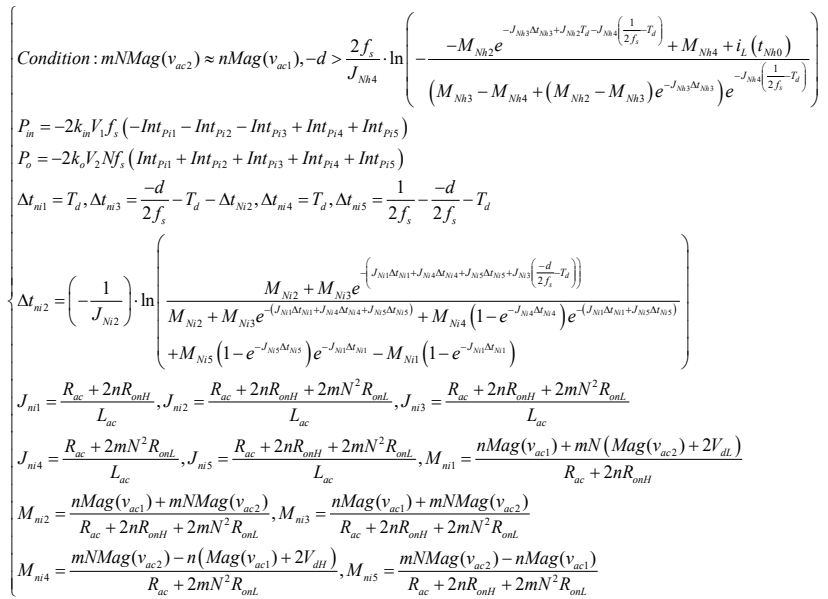

